\title{
LESBIAN HEALTH AND THE ASSUMPTION OF HETEROSEXUALITY: AN ORGANIZATIONAL PERSPECTIVE
}

\author{
ANDREA FILEN DALEY \\ A Thesis submitted to the Faculty of Graduate Studies \\ in partial fulfilment of the requirements \\ for the degree of \\ Master of Social Work \\ Graduate Program in Social Work \\ York University \\ Toronto, Ontario
}

December 1998 
Acquisitions and Bibliographic Services

395 Wellington Street Ottawa ON K1A ON4 Canada
Bibliothèque nationale du Canada

Acquisitions et services bibliographiques

395. rue Wellington Oltawa ON KIA ON4 Canada
The author has granted a nonexclusive licence allowing the National Library of Canada to reproduce, loan, distribute or sell copies of this thesis in microform, paper or electronic formats.

The author retains ownership of the copyright in this thesis. Neither the thesis nor substantial extracts from it may be printed or otherwise reproduced without the author's permission.
L'auteur a accordé une licence non exclusive permettant à la Bibliothèque nationale du Canada de reproduire, prêter, distribuer ou vendre des copies de cette thèse sous la forme de microfiche/film, de reproduction sur papier ou sur format électronique.

L'auteur conserve la propriété du droit d'auteur qui protège cette thèse. $\mathrm{Ni}$ la thèse ni des extraits substantiels de celle-ci ne doivent être imprimés ou autrement reproduits sans son autorisation. 
LESBIAN HEALTH AND THE ASSUMPTION OF HETEROSEXUALITY: AN ORGANIZATIONAL PERSPECTIVE

by

\section{ANDREA ELLEN DALEY}

a thesis submitted to the Faculty of Graduate Studies of York University in partial fulfillment of the requirements for the degree of

\section{MASTER OF SOCIAL WORK}

\section{8}

c

Permission has been granted to the LIBRARY OF YORK UNIVERSITY 10 lend or sell copies of this thesis. to the NATIONAL LIBRARY OF CANADA to microfilm this thesis and to lend or sell copies of the film, and to UNIVERSITY MICROFILMS to publish an abstract of this thesis. The author reserves other publication rights, and neither the thesis nor extensive extracts from it may be printed or otherwise reproduced without the author's written permission. 


\begin{abstract}
This study utilizes a qualitative research design to explore hospital policies and practices to determine whether they reflect a concern for institutional homophobia and its influence on the health care experiences of lesbians as a community of service users. Institutional homophobia is conceptualized as the assumption of female heterosexuality for the purpose of this study. Literature indicates that institutional homophobia, as the assumption of heterosexuality, is implicated in the invisibility and marked visibility of lesbians as service users. Marked visibility refers to the inappropriate focus on lesbian sexuality and is a direct consequence of lesbianism being viewed as problematic, unnatural or pathological.

Eight key informants representing two hospital organizations were interviewed for the purpose of this research. Supplementary data included mission statements, organizational literature, and field notes. Data were analyzed for themes and pattems to determine whether organizational policies and practices reflect an assumption of heterosexuality. The 'findings' from Organization A and Organization B indicate lesbian visibility as fleeting and lesbian invisibility, respectively. These findings support the notion of assumed heterosexuality.

This research exploration adds to the existing literature on lesbian service users by shifting the focus of study from individual to organizational practices. As importantly, the research methodology and design provide a useful framework for exploring the assumptions underlying organizational policies and practices. The ultimate goal of this research is to bring a greater understanding to the ways in which language and assumptions shape knowledge production as well as the construction of lesbian subjectivities and hence, influence organizational policy and practice.
\end{abstract}




\section{ACKNOWLEDGMENTS}

I wish to thank the following people for the support they provided throughout this endeavour:

The participants who made time, especially during these hectic days of hospital restructuring to participate in this research study. Margaret Robbins for listening and providing supportive yet 'critical' feedback. Dr. Patricia Evans for your gentle supervision, invaluable experience, and ongoing confidence. My thesis committee members, Professors Ken Moffatt, Karen Swift and Didi Khayatt for an enjoyable defense. Family and friends for listening to my aches and pains. And last, but not least, my partner Cheryl Murton, Thank you for your care and patience. Thank you for knowing when to nudge and push ... and when not to. 


\section{TABLE OF CONTENTS}

\section{CHAPTER ONE}

\section{Introduction}

Literature Review

Lesbian Health Care Experiences

Discourse on Lesbianism

Conceptual Framework

The Assumption of Heterosexuality 11

Definitions

Lesbian Invisibility

Focus of Inquiry

Research Objectives

\section{CIIAPTER TWO}

\section{Research Framework and Methodology}

Conceptual Framework and the Assumption of Heterosexuality

Conceptual Framework

Post-positivist orientation

Critical Approach to Social Inquiry

Discourse Analysis

Designing the Research

Sample

Data Collection

Data Management

Provisions for Trustworthiness

33

Influencing Factors

34

Ethical Considerations 


\section{CHAPTER THREE}

\section{Findings: Themes and Patterns}

Organizational Profiles 38

Participant Profiles

Themes and Patterns: Organization A

Organizational Knowledge of the Concerns 41

Gay Men as a Vocal Community 47

Organizational Philosophy: Patient Focused 50

Creating Change: Education and Staffing 52

Themes and Patterns: Organization B

Organizational Knowledge of the Concerns 57

The Need for Community Consultations 60

Education as a Means of Change

\section{CHAPTER FOUR}

\section{Discussion}

Differences in Participant Responses 65

Organization A: Fleeting Visibility 66

Organization B: Lesbian Invisibility 67

Implications: Strategies for Social Work

Conclusion

Specificity and Difference

71

74

\section{APPENDICES}

Appendix A

76

$\begin{array}{ll}\text { Appendix B } & 79\end{array}$

Appendix C $\quad 81$

Appendix D $\quad 82$

Appendix E $\quad 84$ 


\section{CHAPTER ONE}

\section{Int roduction}

I have a stronger sense that women who are lesbians don't feel marginalized but sometimes they would prefer that things were done differently like if they were not asked when you last had sex with a man or could they be pregnant. I'm sure that that's a problem that gay women cope with. I wouldn't like to have to explain that all the time. I would like to have the caregiver understand that, maybe, you know, ask the question in a different way.

$$
\text { "Frances", a participant }
$$

Heterosexism within the health care system, specifically the assumed heterosexuality of service users has recently been documented as a serious concern by health care providers and lesbians (Stevens, 1995; Stevens, 1994; Simkin. 1992; Schwanberg, 1990). Institutional practices that assume all women are or should be heterosexual exclude the life experiences of lesbians and renders them invisible as service users. The assumption of heterosexuality affects access to health care services, depersonalised care, and medical decision making for lesbian service users. This research study utilizes a qualitative research design to explore whether hospital policies and practices reflect a concern for the assumption of heterosexuality and its effect on lesbian service users. That is, this research study does not simply seek to determine whether the assumption of heterosexuality exists but rather how the assumption of heterosexuality exists with hospital organizations. This will include an exploration of how macro-level normalizing and individualizing practices (assumed heterosexuality) are indicated by the discursive practices of health care institutions.

The assumption of heterosexuality is often so insistent that practices within health settings do not provide the opportunity for any expression of diversity. In some respects, it 
is a difficult issue to address, in that 'what is not being said' is loud enough to enforce silence. This leads to lesbian invisibility. Our failure to acknowledge heterosexual hegemony fosters the invisibility of lesbians. It is not enough to recognize that some clients may be lesbian, and therefore to incorporate neutral words, such as, 'partner' into our language. This constitutes a passive acceptance of lesbianism, rather than an active analysis of how language and practice enforce a constructed reality (heterosexuality) that does not reflect the experiences of our lesbian clients.

\section{Literature Review}

\section{Lesbian Health Care Experiences}

A review of the literature serves the purpose of (a) introducing some of the health care experiences of lesbians; and (b) presenting the conceptual framework by which the major concepts of this thesis, particularly institutional homophobia will be understood. More specifically, this literature review will highlight how the assumption of heterosexuality can shape lesbians' health care experiences. I suggest that based on the literature the assumption of heterosexuality impacts upon three areas of the lesbian health care experience. These areas include (1) physical needs and help seeking patterns' (2) one's decision to disclose or not disclose sexual orientation; and (3) reactions of health care providers upon clients' disclosure.

Prior to this review it is essential to address the diversity of lesbian communities based on, for example, race, culture, and socioeconomic status and, in doing so, acknowledge that the assumption of heterosexuality interacts with assumptions about these and other elements of diversity. From this perspective, health care experiences within and between lesbian communities in relation to the above stated areas will vary. The inability of 
this researcher to provide a review of the range of experiences based on the diversity of lesbian communities is a reflection of the current state of research in this area and the available literature. Consequently, this researcher acknowledges the use of the term 'lesbian' as problematic in that it assumes a singular construct and a unified experience.

\section{Physical Needs and Help Seeking Patterns}

Stevens (1995) asserts that the assumption of female heterosexuality underlies the structuring of clinical and health education practices and policies in that women's health needs are primarily defined as "reproductive in nature" (p. 26). Cervical cancer screening, for example, is implicitly linked to heterosexual reproductive concerns in that Pap tests are a mandatory precursor to receiving birth control. (Stevens, 1995). This linkage assumes that all women require birth control, and that this requirement provides an effective means by which to ensure preventative screening for women. Moreover, it sends out a message that women who do not require birth control do not require preventative screening, and therefore, are not at risk for cervical cancer. In this way, the assumption of heterosexuality influences health care practice and policy as well as the way in which lesbians interpret health messages.

The assumption of heterosexuality influences the help seeking patterns of lesbian service users. Reagan (1981) found that twenty four percent of lesbians surveyed delayed care because of concerns about negative responses to their sexual preference; Zeidenstein (1990) reported that the majority of research subjects postponed their gynaecological care due to the unpleasantness of 'coming out'; Peteros and Miller (1988) identify the 'largest problem' as lesbians avoiding routine care, thereby, missing routine screenings for breast cancer, cervical cancer and hypertension. Hence, lesbians are more likely than heterosexual 
women to "orient health care around specific health crisis" (Simkin, 1992, p.41).

\section{Disclosing or Not Disclosing}

In reading some of the literature on the health care experiences of lesbians it becomes apparent that a double bind often confronts lesbians as they enter the health care system. This double bind involves lesbians as choosing to either remain silent or to "come out' to health care providers. This is largely a function of assumed heterosexuality; each option equally jeopardises the quality of the health care experienced by lesbians.

Stevens (1994) identifies silence or 'controlling information' as a protective strategy by which lesbians attempt to make interactions with service providers safer. In fact, several studies conclude that many lesbians remain silent for "fear that health care will be substantial or withheld ... fear that providers will moralise to the client or try to change her sexual orientation ... fear that providers will violate their trust and confidentiality." (Gentry, 1992, p. 175). Inevitably, a chain reaction occurs in which lesbian invisibility is enforced as "increasingly, there are very few areas of one's life that one can talk freely about." (Stevens, 1994, p. 223).

Simkin (1992) states that "the assumption of heterosexuality is so strong that lesbians almost always have to volunteer information about our homosexuality" (p. 4l). The strength of this assumption is reflected in study findings which conclude that fifty percent of the male and female physicians surveyed reported that they had never treated a lesbian client (Schwanberg, 1990). Not surprisingly, 'coming out' in health care environments relies upon a considerable amount of courage, especially, in consideration of the power differential that already exists between health care providers and service users (Stevens, 1994; Simkin, 1992). 
Although 'coming out' is not always seen as necessary, several studies have reported that 'coming out' to providers is essential for lesbians and gay men (Robertson, 1992). In fact, research suggests that lesbians from diverse ethnic/racial and socioeconomic communities value the fullness of their health care experience without having to separate off any one part of themselves. One respondent strongly asserted her need for external validation as “a Black woman, a working class woman, a lesbian" (Stevens, 1994, p. 22).

\section{Reactions of Health Care Providers}

A wide range of reactions have been experienced by lesbians upon their disclosure to health care providers. Several studies have reported that often lesbians feel ignored. dismissed, subordinated, silenced, shamed, and denigrated (Stevens, 1994; Robertson, 1992; Denenberg, 1992). In a study by Stevens and Hali (1988), seventy-two percent of the respondents faced negative reactions from health care providers including shock, embarrassment, fear, aloofness, voyeuristic questioning, and inappropriate referrals to mental health professionals. (Steven \& Hall, 1988; Reagan, 1981; Schwanberg, 1990). Moreover, lesbians have reported being handled in a 'rough' manner during physical examinations or having the physician overtly refuse to complete the examination by leaving the room. (Simkin, 1992; Denenberg, 1992). Studies report that both male and female health care providers respond equally in a negative manner. (Robertson, 1992). It is clear that whether we, as lesbians, disclose our sexuality or maintain the veil of heterosexuality we are forced to compromise the quality of our health care and, in doing so, risk our health. 
The invisibility of lesbians as either users or non-users of services - in both cases invisibility is a function of heterosexism - inhibits progress towards identifying a lesbian health mandate. Differences between heterosexual women and lesbians, for example, pregnancy rates, sexual practices, and patterns of alcohol and drug use translate into different health needs (Simkin, 1992). A failure to recognize the implications of assumed heterosexuality increases our vulnerability as a community of service users. As importantly, a failure to recognize how discourse on 'the lesbian' subject maintains the assumption of heterosexuality increases our invisibility as a community of service users.

\section{Discourse: 'the' Lesbian Subject}

Featherstone and Fawcett (1994) define discourse as the way in which power, language, and institutional practices combine at historically specific points to produce particular ways of thinking” (p. 2). Discourse produces particular forms of subjectivity as well as limits on what can and cannot be said within a particular discipline, and therefore is implicit in the relationship between knowledge and social power (Featherstone \& Fawcett, 1994). It is through the various discourses on lesbianism that we come to 'know' the social constructions of 'the lesbian' subject. This knowledge is often a "knowing that is removed from the experiences of lesbians” (Kinsmen, 1996, p. 24).

There is not one but a multitude of forms of discourse on lesbianism. These include religious (homosexuality as a sin), sexology (homosexuality as a congenital disorder), sociological (homosexuality as deviant), medical/psychiatric (homosexuality as a 'condition'), heterosexual feminist (lesbianism as a private choice), and radical lesbian feminist discourse (lesbianism as a political strategy) (Kitzinger, 1987; Kinsmen, 1996; Phelan, 1989; Ponse, 1978). The various forms of discourse interact with and are based on 
social practices. I will focus on the medical/psychiatric, gay affirmative, heterosexual feminist, and radical lesbian feminist discourses for the purpose of this discussion.

\section{Medical Discourse}

The medical (psychiatric) discourse on homosexuality first appeared in the early work of nineteenth century forensic psychiatrists and sex psychologists who identified 'biological degeneration' as a pathological cause of homosexuality (Kinsmen, 1996). Psychiatric discourse constructs homosexuality as "gender inversion", in that "same-sex object choices entail a reversal of gender sex and of sex role"(Ponse, 1978 p. 29). Lesbians are seen to be masculine, while gay men are denoted as effeminate. The notion of gender inversion relies on two major essentialist views. First, that masculinity and femininity are biologically determined (Kinsmen, 1996) and, second, that a natural association exists between gender and appropriate sexual expression; masculinity and femininity are associated with male sexual activity and female sexual passivity, respectively (Kinsmen, 1996; Douglas, 1990; Ponse, 1978).

Through the work of Freud the notion of 'lesbian essentiality' shifted from being considered to be biologically determined to being viewed as psychosexual development gone wrong (Ponse, 1978). Freud theorised that lesbianism was caused by an unresolved female Oedipal complex. The image of the masculine lesbian was conceptualised within women's inability to resolve their attachment to their fathers and to identify successfully with their mothers. Freud's theory presented several ways in which one could fail to resolve the female Oedipal complex, however, the end result is consistently 'the lesbian' subject as essentially sexually immature, regressive, and masculine (Ponse, 1978). 


\section{Gay Affirmative Discourse}

The liberal humanistic model of lesbianism emerged in the mid-1970s (Epstein, 1987; Kitzinger, 1987) and emphasised the right of individuals to "private quests for self-fulfilment and loving interpersonal relationships" (Kitzinger, 1987, p.44). Kitzinger (1987) describes the gay affirmative (psychological) model as one that posits "lesbianism as a normal, natural, and healthy sexual preference of lifestyle" (p.45). As a psychological discourse it constructs 'the lesbian' subject as basically the same as heterosexual women and 'lesbianism' as a "sexual experience that any women could enjoy" (Kitzinger, 1987, p.46). This discourse views homosexuality not as a 'condition', but rather as a form of sexual expression. Discourse on the essentiality of 'the lesbian' subject is replaced by discourse on 'the lesbian identity'.

The construction of lesbianism as 'normal' is complicated by forms of expression that construct the 'healthy' versus the 'unhealthy lesbian identity'. A 'healthy lesbian identity" is achieved through "conformity to middle-class morality and motives" (Kitzinger, 1987, p.51), while an 'unhealthy lesbian identity' is characterised by self-hatred, internalised homophobia, and an inability to integrate one's lesbian identity (Kitzinger, 1987). Subsequently, the gay affirmative discourse does not deconstruct 'the lesbian' subject in need of cure, but rather reconstructs subjectivities that are in need of psychiatric regulation to achieve self-actualization (Kitzinger, 1987). In this way, the essence of 'lesbianism' is not necessarily an internal biological or psychodynamic process, but rather a psychological adaptation to being placed within the category of 'lesbian'. 


\section{Heterosexual Feminist Discourse}

Liberal feminist discourse shares with conventional liberal discourse the attitude that 'lesbianism' is a personal choice, and defines it as largely sex related or as a sexual preference (Kitzinger, 1987). It is, therefore, conceivable that a liberal heterosexual feminist discourse could be characterised by its neglect of 'the lesbian' subject. Featherstone and Fawcett (1994) declare that discursive practices developed in the search for the causes of women's oppression have excluded women who do not fit into liberal heterosexual feminism, including, for example, women of colour, working class women, and lesbians.

A radical feminist analysis of women's oppression is placed in the context of a male/female relationship as well as in relation to women's reproductive freedom (Douglas, 1990). This analysis maintains the assumption that most women are innately heterosexual, and consequently leaves little room for the concerns of lesbians. Heterosexual radical feminist discourse is most likely to construct lesbianism through the stance that the sex of one's partner is irrelevant. Consequently, heterosexual liberal and radical feminist discourses acknowledge lesbianism, but this acknowledgement constitutes a passive acceptance of lesbianism and lesbian realities.

\section{Radical Lesbian Feminist Discourse}

Similar to the medical and liberal humanistic discourses on lesbianism, early radical lesbian feminist discourse constructs 'the lesbian' subject in accordance with the liberal tradition of individualism (Phelan, 1989). In this way, 'lesbianism' is constructed as the 'women-identified-women's' inner struggle for individual freedom and completeness in a sexist and male dominated society. This discourse constructs lesbianism as internal, 
separate from but in opposition to society (Phelan, 1989). Therefore, 'the lesbian' is not socially constructed, but rather continues to be essentially lesbian. This discourse differs from radical heterosexual feminist discourse, in that being lesbian is not viewed as an irrelevant factor, but rather is viewed within a context of struggle and opposition. In relation to medical discourse the difference is one of valuation; medical discourse constructs 'the struggle' as a dysfunctional pathology while lesbian feminist discourse views it as positive self-understanding (Phelan, 1989).

A shift occurred in radical lesbian feminist discourse in response to heterosexual feminism's failure to recognize, and often to disiniss and silence, lesbians within the women's movement, as well as in response to denial within the gay (male) movement that lesbians faced different issues due to their status as women (Phelan, 1989). Integral to the development of radical lesbian feminist discourse was the notion of lesbians as 'gay women' (Phelan, 1989). 'Lesbianism' began to be constructed as a political position as opposed to an internal struggle. From this perspective, 'lesbianism' is viewed as the practical application of feminist theory and 'the lesbian' subject is constructed as a resister to patriarchy (Phelan, 1989). Phelan (1989) asserts that through this shift radical lesbian feminist discourse came to represent "the production of a new truth about lesbians ... the truth that a lesbian is a matter of politics, of rebellion ..." (Phelan, 1989, p.137). 


\section{Conceptual Framework}

\section{The Assumption of Heterosexuality}

The association between assumed heterosexuality and discourse on lesbianism is revealed by a postmodern deconstructive feminist analysis. Deconstructive feminist theory can be distinguished from traditional feminist theories in that it "approaches dominant theories, and their implicit biases, as themselves part of the problem" (Gatens, 1992, p.121). Unlike liberal feminism, it does not extend the terms of 'malestream' theories in an attempt to apply them to women's oppression, nor does it follow radical feminist theory in using women's biology or 'essence' as a means of producing non-patriarchal theory.

Gatens (1992) argues that both liberal feminist and radical feminist theories conceptualize power as "manifested in the regulation and control of politico-economic relations $s^{n}$ (p.124). In doing so, these theories are unable to account for power as an insidious form which produces specific kinds of subjective concepts. This is evident in the tendency for feminism to recreate grand theories based on universal experiences and notions of women and their oppression. An analysis from a postmodern deconstructive feminist position posits that various discourses on lesbianism, such as the liberal humanistic, heterosexual feminist, and medical discourses function as power to produce heterosexual hegemony (assumption of heterosexuality) and, in doing so, silence the voices (experiences) of lesbians. This is accomplished through the process of objectification.

Objectification includes the processes of normalisation and individualisation and functions to exclude lesbians through categorisation and depoliticization. The process of normalisation clearly defines what is normal and what is abnormal in an attempt to assure the conformity of society. The binary terms of heterosexuality/homosexuality, for example, designate the category to which everyone is to belong (heterosexuality) as well as the 
category to which belong only persons who can be differentiated from normal (read homosexual) by categorizing heterosexuality as "unmarked and unproblematized" and homosexuality as "marked and problematized" (Halperin, 1995, p.44). From this perspective, the category of homosexuality does not identify a real class of person, but rather defines heterosexuality by negation and opposition. Through this process the category of 'heterosexuality' becomes contingent upon the problematized category of homosexuality (Halperin, 1995); heterosexuality needs the concept of homosexuality for its own definition. Heterosexuality, by constituting itself as 'normal', defines itself as the opposite of homosexuality, and from this position defines homosexuality as a category to be studied from the subjective stance of heterosexuality. In this way, the category of homosexuality is used both covertly and overtly for assuring heterosexuality (Epstein, 1987).

Medical, liberal humanistic (gay affirmative), and heterosexual feminist discourse that construct the category of homosexuality as a 'condition' and lesbian identity as either 'healthy' or 'unhealthy' constitute normalisation processes. Through such discourses lesbians are divided and excluded as (abnormal) 'Others', and this serves to construct female heterosexuality as 'the' norm. Heterosexual discourses on lesbianism exert power in that, as 'speakers of truth', they constitute a subjective stance which defines lesbianism as 'marked and problematized' (Featherstone \& Fawcett, 1994).

The process of individualisation goes beyond normalization in an attempt to silence the collective voices of the 'Other' (lesbian). Discourse that constructs subjective concepts as individualised by placing lesbianism within the private world of women (Kitzinger, 1987; Halperin, 1995) depoliticize lesbians and lesbianism. Kitzinger (1987) refers to this as "personalisation of the political through an insistent focus on the individual and internal 
as opposed to the institutional and sociopoliticaln ${ }^{n}$ (p.34). Individualisation is an oppressive process which relies on the liberal tradition of 'person-blaming' and, in doing so, silences individuals and ignores the responsibilities of social institutions for social problems (Kitzinger, 1987). Medical (psychiatric) discourse constructs the subject as 'essentially lesbian' due to biological or psychosexual faults. The liberal humanistic and heterosexual feminist discourses construct the subject as 'essentially lesbian' because of a personal preference for same-sex desires. A common underlying theme in the medical and gay affirmative discourses is their emphasis on liberal values, specifically, the value of individualism (Kitzinger, 1987).

Normalisation and individualisation overwrite lesbians' own voices, and “delegitimate our claims to be able to speak knowledgeably about our lives" (Halperin, 1995, p.42). Consequently, we rely on discourse for self-formation and self-identity that define us as 'faulty' and our lives as 'private'. In this way, our invisibility as lesbians lies within the success of discursive practices to normalise and perpetuate the assumption of heterosexuality, and to exclude the realities of lesbians. This process marginalizes 'lesbians' as voiceless 'Others', thereby rendering them invisible.

\section{Leshian Invisibility}

The invisibility of lesbians as users of health care services is rooted in sexist and heterosexist discourse. The recent attention given to both women's (heterosexual) health needs and the needs of gay men living with HIV/AIDS has exposed, albeit minimally, the ways in which sexism and heterosexism have been implicated in the failure of health care to respond to the needs of (heterosexual) women and gay men. Traditionally, a male norm has been used as a yardstick to measure women's health status and needs (Denenberg, 1992). 
More recently, women's (heterosexual) health concerns have been recognised as different from those of men, and thus require a unique definition that does not merely relate to the male norm. Similarly, the health needs and concerns of gay men have been made somewhat visible through the HIV/AIDS crisis and the advocacy work of many gay and lesbian communities (Denenberg, 1992). These developments provide an opportunity to expose a gap in which exists lesbian invisibility.

Although lesbians' health concerns are often the same as those of heterosexual women, our experiences within the health care system tend to be much different by virtue of our 'gayness'(Simkin, 1992). Similarly, lesbians and gay men both experience homophobia and heterosexism within the health care system, however, our experiences as lesbians differ as a result of our status as women (Simkin, 1992). Sexist and heterosexist discourse effectively define all homosexuals as 'men' and all women as 'heterosexual', respectively. In this way, lesbians are constructed either as 'gay (men)' or 'women (heterosexual)' but never 'gay women' (Spaulding, 1993). Consequently, as gay women our lives and experiences remain invisible to our health care providers. 


\section{Definitions}

The following discussion provides a brief overview of some terms/concepts that are relevant to this exploration and understanding of lesbian health care experiences. Although the terms/concepts are presented in a 'fixed' way it is necessary to understand the terms/concepts as existing in variation of subtley, visibility, and expression.

Sexual Orientation is a commonly accepted, scientific term for the direction of sexual attraction, emotional and/or physical attraction, and its expression. Examples include heterosexuality, homosexuality, and bisexuality (Hidalgo, Peterson, \& Woodman, 1985, p.7). The term lesbian refers to a woman whose homosexual orientation is self-defined affirmed, or acknowledged as such. Leshian also refers to female homosexuality oriented (and can refer to women-oriented) ideas, communities, or varieties of cultural expression (e.g., styles, lifestyles, literature, or values), and usually indicates a personal or social identity, normally suggesting that the person has identified herself as lesbian, or that a group accepts or affirms the identification (Hidalgo, Peterson, \& Woodman, 1985, p.8).

Heterosexism is the belief that heterosexuality is the only normal or natural option for human relationships and/or that heterosexuality is superior to homosexuality (Eliason, 1996, p.31). Interpersonal Homophobia occurs when individuals express their attitudes to other people, and can include ignoring, social rejection, name-calling, antigay jokes, verbal threats and intimidation, and physical violence (Eliason, 1996, p.31). Institutional Homophobia refers to the systematic discrimination against lesbian, gay, or bisexual people by the government, educational systems, legal systems, and other major institutions of society. It includes policies and laws that actively exclude lesbian, gay, and bisexual people, or render them invisible by assuming all people are heterosexual (Eliason, 1996, p.31). 


\section{Focus of Inquiry}

This study will utilize a qualitative research design to explore institutional policies and practices to determine whether they reflect a concern for institutional homophobia and its influence on the health care experiences of lesbians. Institutional homophobia is conceptualized as the assumption of heterosexuality for the purpose of this study. My interest in this policy and practice exploration was spurred by reading qualitative sudies on the health care experiences of lesbians, and the assumption by health care providers of client heterosexuality. Literature indicates that institutional homophobia, as the assumption of heterosexuality, is implicated in the invisibility and marked visibility of lesbians as service users. Marked visibility refers to the inappropriate focus on lesbian sexuality and is a direct consequence of lesbianism being viewed as problematic, unnatural, or pathological.

This chapter has presented an overview of the literature relating to the health care experiences of lesbians, discourses on 'the lesbian' subject, and the assumption of heterosexuality. The assumption of heterosexuality by health care providers is a powerful force that shapes the experiences of lesbians and that functions to limit the quality of health care interactions. A focus on the accessibility of services is no doubt essential for the visibility of lesbians and their health care needs. However, it is reflective of a "distributive paradigm" of justice in that it conceives justice "in terms of the allocation of resources and the distribution of access to health care." (Wilkerson, 1994, p.331). This perspective ignores the experience of oppression and marginalization that is a direct result of the institutionalized assumption of heterosexuality, and that often persists despite access to service. 
Iris Young (in Wilkerson, 1994) states that the distributive paradigm of justice functions to "obscure significant and widespread harms experienced by some disadvantaged groups in society, such as homophobia, which is particularly difficult to address within the constraints of the distributive paradigm" (p.331). This means that analysis must extend beyond distributive terms to "include aspects of oppression such as cultural imperialism, exploitation, marginalization, violence, and powerlessness." (Wilkerson, 1994, p.331). Patricia Steven's (1995) article on the structural impact of heterosexual assumptions emphasizes this notion by arguing that studying interpersonal impacts alone is insufficient to explain the barriers lesbians face in health care. Research must also explore heterosexist health care structures including health care policy and practice. As well, Michele Eliason's (1996) "Who Cares: Institutional Barriers to Health Care for Lesbian, Gay and Bisexual Persons" emphasizes the need to both examine and change the institutional practices and policies of health care. Eliason (1996) states that policies must promote the inclusion of all clients/patients and staff in an effort to create an accepting health care environment.

This thesis extends the analysis of institutional homophobia to include an exploration of the policies and practices inferred through the interviews with research participants. The inference of policy was necessary based on (a) hospital organizations not having developed written policy on service provision in relation to lesbian service users; and/or (b) research participants' inability to direct this researcher to such policy. From this perspective, 'policies and practices' are not be understood as “objective accounts" (Smith, 1984 , p. 60) but rather as "subjective processes" (Smith, 1984, p.62) by which the voice of the speaker (research participants) makes visible that which is hidden within fixed texts. From this perspective knowledge production and interpretation is located within 
organizational (local) settings.

In consideration of the above arguement four major objectives were identified for the purpose of this research study. The objectives include:

1) to determine whether hospital and social work policies exist that recognized lesbians as health care service users;

2) to understand the circumstances that lead to the decision to develop or not to develop organizational and departmental policies;

3) to understand the process of policy implementation and its effect on organizational and departmental practices; and,

4) to explore social workers' understanding of the need for organizational and departmental policies that recognize lesbian service users.

A qualitative research design lends itself to the exploratory and descriptive nature of the study as indicated by the identified objectives. The research question and the objectives are characteristic of those framed within an alternate paradigm that values the "discovery dimension of inquiry" (Guba \& Lincoln, 1994, p.106) rather than within the dominant paradigm of positivism which focuses "effort to verify or falsify a priori hypotheses" (Guba \& Lincoln, 1994, p. 106). 


\section{CHAPTER TWO}

\section{Research Framework and Methodology}

I think people are sensitive to the language of the other person so when you hear somebody talking about my partner and then, the staff are, you know, when you talk about how would they know, how would they recognize, I think .. it's interesting I haven't thought about that but I think there has been such education done about being sensitive and using the right word that people now know what to hear...

${ }^{\star C}$ Cheryl", a participant

\section{Conceptual Framework and the Assumption of Heterosexuality}

I argue, in Chapter One, that a postmodern feminist conceptualization posits that the assumption of heterosexuality is the product of discursive practices that normalize heterosexuality and individualizes lesbianism within historical, political, and cultural contexts. I also propose that the focus of inquiry includes looking beyond the allocation and distribution of access to explore institutional homophobia (assumption of heterosexuality) as reflected in hospital policies and practices. Conceivably, this requires a research orientation that will function to uncover hidden truths and assumptions; that will support the exploration of knowledge production and the functional power of language; that will allow for the discovery of 'what' we know and, as importantly, 'how' we know. I will argue that a critical approach to social inquiry will provide the appropriate tool for this task. The following discussion will highlight the conceptual framework of this research through an examination of the post-positivist orientation, the critical approach, and discourse analysis 


\section{The Post-Positivist Orientation: Rationale for a Qualitative Design}

Hawkesworth (1988) suggests that the goal of the post-positivist research process includes contributing to "emancipatory objectives by weakening myths, refuting distortions, and preventing an imbalanced view of social reality" (p.31). The post-positivist conceptualization of knowledge as contextualized and its recognition of the role of values suggest that a qualitative approach would best serve this identified goal. Proponents of the post-positivist orientation rely on qualitative methodologies to "cultivate greater understanding of human reason" (Hawkesworth, 1988, p.31) by identifying the "diverse dimensions of debate pertinent to particular policy questions" (Hawkesworth, 1988,p.31).

The specific critical viewpoints espoused by the proponents of the post-positivist orientation address the positivistic definition of knowledge as empirical facts and the notion of value neutrality (objective knowledge). Hawkesworth (1988) identifies these criticisms as the critique of ideology and the critique of politics, respectively.

The post-positivist critique of ideology states that defining usable knowledge as empirical facts is arbitrary and supports an ideology which posits that we can not know what science does not tell us. Proponents of post-positivism view this ideology as a form of idealism which is based on mistaken beliefs about human reason, and which functions to limit the expression of certain questions (Hawkesworth, 1988). Paris and Reynolds (1983) discuss the 'limitation of expression' through an exploration of the positivist notion of human activity. The authors (1983) suggest that the positivist assertion that subjectively meaningful behaviour is a factual phenomenon like any other subject for scientific study» (Paris \& Reynolds, 1983, p.168) means that we can only come to 'know' (have knowledge about) human activity through rigorous scientific methodology. This view does not represent an "agentistic" orientation to human activity because when exploring "what 
people do, notions such as reason, intention, and purpose do not come into play" (Paris \& Reynolds, 1983, p.167). Of equal importance, is the argument that the positivist definition of usable knowledge limits the construction of knowledge by ignoring its' existence within historical and cultural contexts.

The post-positivist critique of politics addresses the positivist notion of the researcher as a value-free and "passive observer of contemporary events" (Hawkesworth, 1988, p.28). Rather than supporting the myth of objectivity proponents of post-positivism view science as a value-laden political force that "establishes the parameters for contemporary consideration of political questions" (Hawkesworth, 1988, p.28). In this view, the failure of positivism to address the question of values in the research process is seen as morally dubious (Paris \& Reynolds, 1983; Hawkesworth, 1988).

\section{Critical Approaches to Social Inquiry}

Critical theory, as a post-positivist approach, posits that there is a real world, although it does not consist solely of neutral facts that are independent of values and theories (objectivity). The critical approach argues that objectivity does not necessarily mean being value free but rather means providing a non-distorted, true picture of reality. This can be achieved by adopting a position of historical realism in which "reality is seen as constantly shaped by social, political, cultural, and similar factors" (Neuman, 1997, p.75). From this perspective, 'reality' is conceptualized as existing within located, micro-level subjective meanings as well as within a larger, macro-level historical context.

Critical theory views social inquiry as a "moral-political activity that requires researchers to commit to a value position" (Neuman, 1997, p.79). The critical theory approach to social inquiry conceptualizes values as a necessary component of usable 
knowledge that are uncovered through the research process. In this way, knowledge is seen as power in that what is studied and what happens to the results involves values and morality. The goals of the research process as identified by critical theorists are to discover deep structures, to confront injustices, and to achieve the empowerment of individuals (Neuman, 1997). Rixecker's (1994) discussion of feminist standpoint epistemology provides an appropriate platform for exploring further the critical theory of knowledge, particularly, the issue of values and knowledge

Feminist standpoint epistemology is defined by Rixecker (1994) as a viewpoint which attempts to address the ahistorical, culture-blind knowledge construct and an attempt to dismantle the theoretical and practical discursive power structures of traditional epistemic stances" (p.126). Feminist standpoint epistemology argues that reason and emotion should not be viewed as separate because knowledge creation incorporates the use of feeling and intuition; elements which have been marginalized by traditional Western epistemic construction. Consequently, feminist standpoint epistemology posits that knowledge is not value-free but rather is a reflection of our interpretations of our experiences, thereby, relying on reason and emotion.

Context is viewed by feminist standpoint epistemology as a necessary component of reality construction in that knowledge is conceptualized as reflecting a situated view of reality. In this way, knowledge is seen as temporary, changing, and fluid. In the construction of knowledge, feminist standpoint epistemology argues not for the abolition of "objectivity" but rather for a reconstructed definition. Hardy (in Rixecher, 1994), for example, critiques the traditional construct of objectivity as being both too broad and too narrow. Objectivity as defined by positivism is too broad in that as a "value-free construct it necessitates the absolute elimination of all values within research, and too narrow in that it 
"is a construct of value agreement between and among specific researchers" (Rixecher, 1994, p.122), namely those within the scientific community. In this way, the positivist construct of objectivity illustrates the way science has been constructed by Western, bourgeois, and patriarchal values and interests. That is, the value agreement serves the interests of the (male, heterosexual) elite, and thereby, marginalizes the perspectives and interests of "Others". Alternatively, Hardy (in Rixecher, 1994) argues for "strong objectivity" in that it is inclusive of historically and socially situated contexts and functions to construct a partial and locatable critical knowledge, hence, avoids constructing knowledge as relative (the interpretist approach) or as a totalization (single vision) (positivism).

Adopting a critical qualitative approach corresponds both with my conceptualization of institutional homophobia within a postmodern feminist orientation and with the focus of inquiry as earlier presented. A postmodem feminist orientation posits that institutional homophobia as the assumption of heterosexuality is achieved through discursive practices that function as power to marginalize lesbians as voiceless "Others". The critical approach to social inquiry is useful for developing and expanding the repertoire of research questions that aim to understand the assumption of heterosexuality within hospital organizations. That is, research questions must reach beyond the isolated phenomenon of individual behaviour to include an understanding of the ideology of the organization as indicated through organizational practices. Research questions must be framed in such a way as to uncover values and norms as well as to identify gaps and silences. The latter is of particular importance in that "in silences is located aspects of social existence that are repressed, driven underground by the power of history" (Danzinger, 1995, p.440). 
The critical approach is also useful in that it accepts my value position as a lesbian researcher. This research is not simply an academic exercise but rather represents a political exploration of oppression and marginalization. As a lesbian researcher working from a critical perspective I am not obliged to adopt a neutral, objective stance (nor pretend). Conversely, I am obliged to acknowledge that my position (experience) as a lesbian will be an integral part of knowledge production.

\section{Discourse Analysis}

Harriette Marshall (1994) suggests that language plays an active constructive role in social inquiry, and therefore, argues for the rejection of the realist assumption of language as a "transparent medium which is thought to reflect reality unproblematically" (p.92). In this way, Marshall (1994) conceptualizes language as a tool by which one's orientation to humanity (action) and society may be understood. Following this, the advocates of language analysis view social inquiry as a "distinct language game" in which language becomes the object of study in its own right (Marshall, 1994).

Stubbs (1983) suggests that a major difficulty in defining discourse analysis is both its vastness and lack of focus. Subsequently, the most direct and conceivably the most naive means by which to describe discourse analysis is through a simple statement. Nye (1994) states that the term discourse analysis is used broadly to "encompass a number of different and sometimes incompatible approaches to talk, including transactional analysis, sociolinguistics, speech act theory, and conversational analysis" (p.216). Modern discourse analysis assumes that language, action, knowledge and power are inseparable (Stubbs, 1983). In this way, utterances are not considered only as sentences but also as a form of social action (Stubbs, 1983; Van Dijk, 1993). Stubbs (1983) asserts that based on 
this assumption modern discourse analysis addresses "the depth of indirection" (p.4), or rather, "the distance from surface linguistic forms to understanding social meaning" (p.4).

A systematic analysis of discourse provides an interdisciplinary description of the levels or dimensions of discourse as well as a functional account of language. This is accomplished by making explicit how each element of discourse (text and talk), for example, semantic structures of sentences and sentence pairs, semantic macrostructure of sentence sequence and whole texts (topics and themes), cohesion relations, intonation, and lexicalization (selection of words) contributes to social processes involved in communication (Stubbs, 1983; Van Dijk, 1993). Van Dijk (1990) refers to this level of analysis as contextualizing discourse with respect to the structures of the social situation at the micro-level. This approach presents a more expansive approach to discourse analysis.

Van Dijk's (1993) multidisciplinary approach to understanding the reproduction of racism represents a shift away from the use of discourse analysis as an apolitical, microlevel enterprise towards that of a more socio-political enterprise. The previous discussion suggests that discourse analysis has traditionally paid attention to the structures or strategies of text and talk rather than to the conditioning or conditioned structures and processes of the social context" (Van Dijk, 1990, p.7). Van Dijk (1990) argues that analysis must extend beyond that of micro-level, social constraints (conversational universals, personal strategies or micro-context) to include the macro-constraints of "social and political structure" (p.7). Within this shift lies the potential of discourse analysis to bridge the gap between micro and macro-analyses of social action.

Van Dijk's framework is relevant to this research, particularly the concept of assumed heterosexuality and normalising and individualising practices. A postmodern conceptualization implicates discourse and social practices in the construction of assumed 
heterosexuality at the micro-, meso- and macro-levels. This research exploration will, in some way, attempt to 'capture' the reproduction of macro-level normalising and individualising practices (assumed heterosexuality) as indicated by the discursive practices of health care institutions. Van Dijk's critical discourse analysis is useful in that it proposes a theoretical framework that highlights the interdependency of the micro- and macrostructures.

A critical discourse approach to data analysis will provide a tool for examining the language of respondents as reflections of organizational ideology. Marshall (1994) suggests that the research interview "is no longer seen as a means of measuring the genuine views of a participant but as a means of exploring the varied ways of making sense" (p.95). That is, the focus becomes the identification and description of repertoires and the consequences of their use within a particular context (Marshall, 1994). This means that concern is at the level of discursive practices rather than the individual interviewee. Conceivably, data analysis must go beyond "what" is stated to analyze "how" it is stated. The critical discourse approach also proved useful during the cross-comparative data analysis process. That is, as I analyzed the data for meaning units and themes this perspective on the functional power of language influenced my interpretation of the speakers' words and meaning. Subsequently, 'discourse analysis' was indirectly 'applied' during the cross-comparative process.

Danziger (1995) asserts that when language is taken for granted "we conceal the potential to limit, exclude, distort, or manipulate" (p.441). Of analytical importance, for example, is not necessarily whether or not lesbian health issues have been identified as a concern, but rather, the language used to describe the history and processes involved in this decision (either way). 


\section{Designing the Research}

\section{Sample}

Research Participants. Two hospitals located in the downtown core of Toronto were selected as the sample population. The selection of hospitals was made with respect to geographical location, particularly, their proximity to the Church St. and Wellesley St. area. This area is comprised of a large lesbian and gay population as well as consisting of many lesbian and gay commercial businesses. In this way, the hospitals chosen would have an equal likelihood of providing services to lesbian clients.

It was difficult to decide a priori how many hospitals to include. However, the emergent qualitative design utilized provided flexibility and as the study progressed this researcher explored the possible need of including new hospitals based on data collection and analysis. The decision to include new hospitals was mediated by the limitations of time and accessibility to policy documents and participants.

Participant Characteristics. The sample includes a total of eight research participants from the hospital organizations. These include six participants at the organizational (administrative/managerial) level and two practitioner (social worker) participants. The subgroups provide an opportunity to explore the issue of assumed heterosexuality at varying levels ranging from those who have direct contact with clients (social workers) to those who carry a more administrative role within the hospital organizations (hospital administrators). The selection of participants at the social work department level represents an important link between front line workers and organizational administrators. The purpose of this approach is to develop a fuller understanding of how policies are perceived as reflecting a concern for institutional homophobia within the hospital environments. 
Locating Interviewees. Formal institutional channels were utilized to locate participants at the organizational level within each hospital. This included contacting the Public Relations Department regarding both the existing organizational policies and potential research participants. Initial contact with Public Relations included an introduction of the research topic, academic affiliation, and a general description (as above) of potential research participants. This was followed by the submission of a written request (Appendix $\mathrm{C}$ ) and resume (Appendix D). Each organization responded with a request for a protocol summary for review by the hospital ethics committee and a letter written by my thesis supervisor outlining the ethics review procedure at York University. Upon approval by the ethics review committees, I was referred to a contact person at each hospital who provided the contact names and numbers of research participants.

\section{Data Collection}

Interview Schedule and Guide. This study employed semi-structured in-depth interviews. Face-to-face interviews were directed in one of two ways. First, an interview schedule (Appendix A) consisting of a detailed set of open-ended questions was developed for interviewing participants at the organizational (administrative/managerial) level. This approach was chosen as a means of collecting parallel data from each hospital. Second, an interview guide (Appendix B) was utilized during interviews with social worker/practitioner participants. This approach was chosen as a means to elicit from participants what is perceived as important within broad boundaries of interview topics. As well, the presentation of broad interview questions provided more opportunity for the use of each interviewees' unique language and meaning of institutional homophobia or assumed heterosexuality. 
The development of the interview questions were evaluated with respect to (1) clarity - having a clear focus; (2) complexity - ensuring that each question is a singular question; and, (3) structure - ensuring that each question was open-ended (Maykut \& Moorehouse, 1994). As well, the sequencing of questions were developed in reference to question typology as defined by Patton (1990). That is, questions were identified as either experience/behaviour, opinion/value, feeling, knowledge, sensory, or background/demographic questions. Foliowing this, questions were sequenced in accordance with the following three considerations:

1) Interviews will be started with non-conversational behavioral/experience questions framed in the present.

2) Potentially threatening knowledge questions will be delayed until some rapport has been established.

3) The number of background and demographic questions will be minimized and interspersed.

(Maykut and Moorehouse, 1994)

Interview Process. Initial contact occurred by telephone. I introduced myself by stating my position and university affiliation, and provided a brief overview of the study. The telephone call was followed by a letter which explained in more detail the purpose of the study (Appendix C). I also included a resume in an effort to provide background information on my educational and employment experience (Appendix D). This was followed by a second telephone call in which I arranged for an interview meeting time and place; each participant was provided, in advance, with a copy of the protocol summary.

Each interview began with a personal introduction, and a statement of purpose including what will be done with the results of the study. This was followed by a statement of why the particular interviewee has been selected. As well, a consen/confidentiality form (Appendix E) was explained and presented for both interviewer and interviewee signatures. 
A copy of the form was given to each research participant.

The participants were interviewed for approximately one hour in length. Maykut \& Moorehouse (1994) suggest that a one to two hour interview allows time for the interviewer "to establish rapport with interviewee and to foster a climate of trust"(p. 81). The participants were interviewed on one occassion only. Verbal consent was received for a second interview to pursue subsequent interview topics that emerged from preliminary data analysis. Second interviews were not required. The interviews occurred within the hospital environment, either in the participants' office or in a place mutually agreeable to participant and interviewer. Interviewees were reminded of the voluntary nature of their participation and their right to discontinue participation at any time during the interview.

I gave consideration to the difficulties that may have been experienced with respect to accessing participants that hold elite positions within hospital organizations, and the power imbalance that may exist between this researcher and participants based on these positions. Particulary, I anticipated barriers with respect to accessing administrators as compared to administrative assistants or public relations personnel. This held true for each organization in that I was unable to access, for example, the Vice-President of Patient Care Services but rather was referred to an employee/committee member within that area.

Special effort was made to avoid an elite interviewee from turning the interview around, thereby, taking charge of it (Marshall \& Rossman, 1995). Although, none of the research participants took 'charge', one participant in a managerial position did make it clear through body language and tone that the focus of inquiry (line of questioning) should be redirected. Questions exploring organizational knowledge about the concem and/or issues of lesbian service users were asked on three different occasions throughout the one hour interview. The interviewee responded to each inquiry by redirecting the question; 
during her final response the participant shifted her body away from the interviewer (turned sideways in her chair) and changed her voice tone while continuing to redirect the focus of inquiry. These action were interpreted by this researcher as a clear signal to discontinue the focus of inquiry.

\section{Data Management}

Transcription. Interviews were audiotape recorded and immediately transcribed into typed form using a transcriber and word processor. Audiotapes were replayed in an effort to 'capture' the subtlety of language - intonation, pauses, and emphasis - of participant responses. Several photocopies of each transcribed document was made for the purpose of data analysis. Research field notes of each interview recorded my subjective experience of the interview as weil as relevant observations (ie., the body language of participants) A request was made of organizational and departmental participants for one copy of existing policies or mission statements.

Data Analysis. An inductive, interpretive-descriptive approach in combination with the constant comparative approach to data analysis was used for first level analysis (see Maykut \& Moorehouse, 1994); second level analysis utilized discourse anlaysis as discussed in the previous section. This combined approach reflects the explorative and descriptive nature of the proposed research question. That is, the primary goal of data analysis was not to 'fit' data into predetermined categories but rather to select and interpret the emerging data in an effort to understand the phenomenon of assumed heterosexuality and organizational policy and practice. 
Each transcript and policy document page was coded for identification purposes. The data from each transcript and policy document were unitized following the procedure outlined by Maykut and Moorehouse (1994). Once the unitizing of data was complete, the constant comparative method (Maykut and Moorehouse, 1994) was applied for data analysis in an effort to establish outcome propositions or rather outcomes of the study. The major steps of this process included:

1. Coding Data Pages:

2. Unitizing the Data

3. Inductive Category Coding - Constant Comparative Method

4. Refinement of Categories - Rules for Inclusion

5. Exploration of Relationships and Patterns Across Categories 


\section{Provisions for Trustworthiness}

To establish the 'truth value' of this research study four constructs of trustworthiness as outlined by Marshall and Rossman (1995) were utilized. The four constucts were identified as credibility, transferability, dependability, and confirmability.

Marshall and Rossman (1995) state that the goal of the construct of credibility is "to demonstrate that the inquiry was conducted in such a manner as to ensure that the subject was accurately identified and described" (p.143). Credibility is ensured by adequately stating the boundaries or parameters within which the data will be collected. In the case of this research study credibility was achieved by (a) accurately defining the research participants; and, (b) following the procedures established for locating interviewees and performing interviews.

Transferability refers to the generalizability of the findings and is accomplished through the use of multiple sources of data. Using multiple sources increases the likelihood that institutional homophobia as a phenomenon is "being understood from various points of view and ways of knowing" (Maykut \& Moorehouse, 1994, p.146), and therefore, strengthens the usefulness of this proposed research design and methodology for understanding the phenomenon of institutional homophobia within other settings. This study relies on multiple participants as well as two data types in an effort to elicit different perspectives, and therefore, to achieve transferability.

Dependability requires that the researcher "accounts for changes in the phenomenon chosen for study as well as in changes in design” (Marshall \& Rossman, 1995, p.145). For the purpose of this study, dependability was achieved by maintaining an audit of data management and data analysis. The audit consists of a journal that records each research decision and the rationale behind it. This will allow other researchers to inspect the 
"procedures, protocols, and decisions" (Marshall \& Rossman, 1995, p.146), and therefore, also functions to satisfy the question or 'replicability' as it applies to qualitative research (Marshall \& Rossman, 1995).

Confirmability of the research outcomes was addressed in three ways. First, through a careful evaluation of whether the data confirm the general findings and lead to the implications. Second, by maintaining a record of each transcript for references and checks. Third, through the appointment of a 'research partner' to critically question this researcher's analysis (Marshall \& Rossman, 1995).

\section{Influencing Factors}

In consideration of the post-positivist orientation to this research exploration I have chosen to identify 'factors' as those that have functioned to influence rather than to limit this research process. This discussion will identify two influencing factors; these include the location of the researcher and the readers, and the fluidity of the participants' subject positions.

\section{Researcher's Location}

Most, if not all, of the literature that I have drawn upon for this research thesis comes from the world of academia, particularly from the medical, psychology, political science, and social work disciplines. These disciplines are overwhelmingly represented by largely a liberal, white, middle-class position by either men or women, and therefore, lack diversity with respect to experiences and perspectives. Consequently, this literature is limited in that it is does not represent all of the experiences nor the needs of all lesbians. 
As well, I write from a white, 'middle-class', feminist, lesbian position while acknowledging that lesbian communities are diverse in terms of ethnicity/race, socioeconomic position, education, sexual expression, political viewpoints and ideology, gay politics, and life experiences. Therefore, I do not nor am I capable of, speaking for the whole of the lesbian communities. My position is one of both privilege and oppression; privileged as white and middle-class and oppressed as a lesbian and a women living within heterosexist and sexist power structures. In taking this position I recognize the parameters of my analysis and welcome discussion and feedback.

In recognizing my own location I also acknowledged the various subject positions of the audience, or rather the readers of this thesis. Acknowledging the various subject positions of the readers, particulary as determined by sexual orientation required that I examine the implications of my analysis from various perspectives. That is, in what ways could my analysis be read/understood/interpreted by heterosexual, lesbian, and gay readers?

\section{Participants' Subject Positions}

The eight participants interviewed represented diverse positions determined not only by organizational role but also by ethnicity/race, sexual orientation, gender, and political philosophies. Of particular relevance to this research was the inability/difficulty (or reluctance) of the participants to speak openly from their various subject positions (except for one participant who identified herself as lesbian) while representing the organizational 'voice'. Conceivably, this phenomenon reflected a 'loyal' and/or 'protective' organizational discourse, and manifested itself as discomfort and/or ambivalence as expressed by participants during the interview process. Participant discomfort and/or ambivalence was 
most apparent during responses to inquiries about concerns and/or issues for lesbian service users. The majority of participants did not answer the question(s) or responded in a general and vague manner about meeting the diverse needs of clients.

\section{Ethical Considerations}

The development of the research design included the consideration of both generic ethical concerns and 'situation-specific ethical concerns (Marshall \& Rossman, 1995). The generic concerns included assuring both participant confidentiality, and that participants were informed of the purpose of the research. I addressed these concerns through (a) the follow-up letter which explains the purpose and affiliation of the proposed study; (b) the informed consent/confidentiality form; and, (c) the permission form to audio tape the interview. As well, the ethical concern of 'scholarly conduct' was considered, in that, the research design provided opportunity for the examination of the emergent design development, data collection techniques, and the raw data. These measures functioned to ensure that data was not falsified nor distorted.

'Situation-specific' considerations included ensuring that participants were not emotionally or psychologically harmed in the course of the interview process. All respondents were informed of their right to discontinue participation at any time during the interview process. This is particularly relevant to this study of homophobia in that respondents may experience anxiety or discomfort if they are coping with issues around their own or others' (ie., daughter, sister ) (homo)sexuality. This consideration also took into account the strong moral, religious, and political positions often associated with the topic of (homo)sexuality. Although this researcher prepared for such considerations, research participants did not appear to experience anxiety nor discomfort as directly related 
to the issues of lesbianism and sexuality.

Ethical considerations also included ensuring the anonymity of the hospital organizations in an effort to protect participant confidentiality. Organizational anonymity was adopted in recognition of (a) the 'loyal' or 'protective' organizational discourse previously discussed, and in an effort to reduce discomfort and/or ambivalence; and, (b) the size and distinct characteristics of the hospitals which could, in turn, facilitate the identification of research participants. This was particulary relevant to May who spoke critically about hospital policy from her position as the only 'out' lesbian within her department. Interestingly, my ethical responsibility to May was not based solely on my position as researcher but also on my position as a lesbian. Lesbians and gays often protect one another within families, schools, workplaces, and neighbourhoods; we do this, among other ways, through subtle acknowledgement of one another and a shared understanding of the risks of being 'out'. My ethical responsibility, as a lesbian, to 'protect' May was also implicated in the cautiousness applied when selecting excerpts from May's transcript. 


\section{CHAPTER THREE \\ Themes and Patterns}

I think there's still .. in spite of people who like to see themselves as well informed and aware and alternative I still think that there is the notion of heterosexuality as the norm. It still or, or, or not even maybe so much the norm but perhaps percentage wise.. the, you, know I don't think it crosses their mind half the time, I mean, it's so entrenched this notion that .. a women walks into your office and you don't even think whether she's straight or gay - it's just there in your consciousness and they proceed by assumption ...

"May", a participant

The chapter begins with a profile of the organizations and the research participants prior to presenting the research findings. The discussion presents information about the organizations and the participants in an integrative and general way in an effort to maximize confidentiality and anonymity. For this reason, profiles will not be structured by identifying a specific organization nor participant. This researcher acknowledges that such an approach carriers the potential of limiting reader interpretation in that organizational and participant profiles can not be matched with specific findings. Of importance to this research endeavour is the understanding of the 'cumulative' findings, or rather the 'totality' of knowledge/experiences as presented by the organizations.

\section{Organizational Profiles}

The hospital organizations that participated in this research study are located in downtown Toronto and within close proximity to the 'lesbian and gay community' as geographically defined by Church Street and Wellesley Street. In combination the hospital organizations recognize several diverse populations and their unique health needs; these 
include the homeless, consumer/survivors, the poor, refugees and immigrants, lesbians and gay men, and women. Various in-patient services, outreach programs, and initiatives address issues specific to these communities including culturally-specific services, sexual and physical assault/bashing, mobile treatment units, and crisis teams. Each organization has a broad mission statement that recognizes and pledges themselves to respond to the diverse needs of their patient communities. As indicated by the participants' responses to this researcher's request for policies related to racism and discrimination neither organization has developed such a policy.

The physical cues and symbols that signal the inclusive of lesbians in the hospital organizations were fairly minimum. Each organization provided some informational pamphlets and flyers about gay positive support services and groups, for example, counselling groups for lesbian women with addictions, services related to HIV/AIDS. One hospital organization 'flew' the rainbow flag (hung on a wall in one department) - a symbol of recognition and acceptance within lesbian and gay communities.

\section{Participant Profiles}

All of the research participants interviewed were women and represented diverse racial/ethnic communities; these included Chinese (1), Trinidadian (1), South Asian (1), and European and Anglo-Saxon (5). The organizational positions held by the participants included program director, departmental manager, social worker, outreach worker, and clinical nurse specialist. Participants were linked with various service areas including emergency services, counselling services, access and diversity committees, and clinical services. One participant self-identified as lesbian; one participant self-identified as nonlesbian (did not identify herself as heterosexual but stated "I guess it's becoming obvious that I'm not .. uhm .... lesbian"). 


\section{Findings}

The process of data analysis took approximately six months beginning from the first participant interview in January, 1998 and ending with the last participant interview in June, 1998. The transcripts were coded in sequence of the interview schedule meaning that all transcripts from Organization A were completed prior to Organization B. The following discussion will present relevant findings as indicated by two levels of data analysis. First level analysis yields common themes between the participant responses through the use of the cross-comparative method. Second level analysis involves the use of discourse analysis and reveals relevant findings related to language and speech patterns. Although, second level analysis does not produce independent themes, it does prove useful for highlighting values and beliefs associated with (homo) sexuality.

The process of data analysis reveals a different yet parallel 'set' of themes as related to the transcripts from each organization. Based then on this finding the themes will be discussed within the following sections:
1. Organization A
2. Organization B 


\section{Organization $\mathbf{A}$}

Four major themes have been identified through the data analysis of the transcripts from Organization A. The participants representing Organization A include: 'Frances', 'Ellen', 'Cheryl', and 'Liz'. The following discussion will present the major themes:

\section{Theme \# 1}

Organizational Knowledge of the Concerns and/or Issues of Leshian as a Community of Service Users.

All four of the participants from Organization A responded to questions exploring organizational knowledge about specific concerns and/or issues raised by lesbian communities or from within the organization and as related to the needs of lesbians as a community of service users. Participant responses suggest an inconsistent level of organizational knowledge and sensitivity to the concerns and/or issues of lesbian service users. Moreover, participant responses reflect a degree of discord between individual and organizational knowledge and sensitivity to the concems and/or issues. These findings are most appropriately represented as two sub-themes which emerged through the crosscomparative data analysis. The sub-themes include (a) organizational knowledge and sensitivity as inconsistent; and, (b) a recognized gap between organizational knowledge and individual knowledge.

\section{Organizational knowledge and sensitivity as inconsistent}

Inconsistency is represented by an analysis of the range of participant responses which include a self-identified lack of organizational knowledge to an identification of 'local' or departmental knowledge and sensitivity. Prior to beginning this discussion, it is 
necessary to emphasize that the analysis does not reflect individual knowledge but rather represents the distribution of knowledge and sensitivity within the organization.

Cheryl's response as an employee within the organization whose role includes, among other things, addressing client diversity and accessibility is particularly revealing in that she openly and comfortably declares herself "the wrong person to ask". Cheryl does not identify her lack of organizational knowledge as problematic nor does she acknowledge a sense of needing to know but rather refers this researcher to other participants involved with organizational initiatives that address HIV/AIDS as well as specific initiatives as related to the lesbian and gay community(s). Cheryl's openness and the general ease by which she refers this researcher to 'those in the know' suggest a degree of acceptability of inconsistency as related to organizational knowledge and sensitivity to the needs of lesbian service users.

Although Cheryl is unable to discuss organizational knowledge specific to the concerns and/or issues of lesbian service users she does provide insight into organizational knowledge production and it's relationship to the notion of inconsistency. The speaker explains that the organizations conception of clients' needs exists within the context of specific programs. Cheryl states:

... what we had hoped was that systematically we might be able to set up some sort of consultation, key people to say, you know, to programs, o.k. we are developing this new initiative have you thought about this community, that community, that community, how is it going to play out, how is it going to be different.

In this way, organizational knowledge is the outcome of a consultation process by which new initiatives are explored in relation to specific communities of service users. This process highlights the need for community representation during the program development stage. Cheryl's description of knowledge production as program driven supports the notion 
that knowledge and sensitivity could vary from program to program depending on the identified relevance of the initiative to each community. This could be determined by (a) "who" represents communities - are subcultures within communities identified; (b) "who" defines relevancy; and, (c) "how" relevancy is defined - is it defined within the traditional heterosexist and sexist structure. A lesbian sexual orientation, for example, may be identified as relevant to stereotypical health issues related to women such as gynaecology but identified as irrelevant to health concerns related to cardiology and renal function. In this way, the realities and experiences of lesbian services users become compartmentalized, and the visibility of lesbian services users (lesbian subjectivity) becomes fleeting (fluctuates). Conceivably, the wholeness of one's experience as a lesbian could depend largely on the diagnosis/event/program.

Data analysis provides further support for the theme of 'organizational knowledge and sensitivity as inconsistent'. Frances, for example, when discussing general lesbian concerns and/or issues such as inappropriate history taking delimits her response by stating "I couldn't speak for other areas of the hospital". This analysis suggests that although concerns and/or issues may be 'universally' experienced by lesbians service users within the hospital organization knowledge exists at a local (departmental) level.

This notion is also supported by Liz's response to this researchers inquiry about changes in the culture of the organization. Liz differentiates between the culture of one specific department and the general culture of the organization by stating "I don't think it's changed that much .. I think we're on the edge here .. I don't think it's changed that much in the hospital at all". The analysis of the excerpts from Frances and Liz highlight the role of 'relevancy' in defining the totality of one's experience. From this perspective, lesbian service users cannot be assured that all service providers would be knowledgeable or 
sensitive to their concerns and/or needs.

Recognition of the gap between organizational knowledge and individual, knowledge.

Participant responses suggest an informal 'way of knowing' that is not integrated into the overall framework of organizational knowledge but rather that exists as bits and pieces. Participants recognize informal knowledge from a more personal, individual perspective, and in doing so, appear to experience discord. Ellen, for example, cautiously responds to a question about whether there has been discussion about lesbian concerns and/or issues by stating:

It's been discussed but not to a large degree. No. It's, it's certainly been discussed at, at, at some of the (committees) and how like, in the (clinic) ... and same-sex couples, uhm and, and, how do you, you know, make sure that, that, you know ... you ask if someone wants somebody with them you don't assume that they'll have a husband or a wife, uhm, that's a different gender ... and so, there's been conversation at, at staff meetings around those uhm, but nothing, uhm, no. Nothing in a formalized way at all. No.

Ellen describes 'discussions' of the concerns in the context of staff meetings while acknowledging a lack of 'formalized' organizational knowledge. This analysis suggests that Ellen's response conveys a recognition of organizational knowledge and sensitivity as informal. Unlike Cheryl's open and direct response, Ellen's 'cautiousness' suggests a degree of uneasiness with this recognition.

Moreover, data analysis reveals discord as a result of a recognized gap between organizational (formalized) knowledge and individual (informal) knowledge. For example, although Ellen previously submitted that lesbian concerns and/or issues have not been discussed in a "formalized way", she reveals a more personal, individual 'way of knowing' by stating: 
Well ... I don't know, like ... I certainly wouldn't pretend that there aren't probably issues 'cause I can't imagine that they're not given what happens when you go to a doctor sometimes, uhm ... but, the issues haven't come forward very strongly so, uhm .... it's hard to kind of push it ....

In a similar vein, Frances identifies some of the concerns and/or issues for lesbian service users by stating that:

gay bashing, assaults, uh, fear of stigma has been very strong, uhm, to a lesser degree the, uhm, concern has been raised around just the fact that women, how lesbian women are treated .. they're asked all of the same kinds of questions, for example, when sexual history is proposed or asked for, uh, when you're a gay women there's no understanding of the fact that maybe this person isn't having sex with men, so .. the questions aren't tailored to reflect that.

Frances goes on to negate this as organizational knowledge by classifying these concerns as "general scuttlebutt" that have not been a "strenuous concern" to this particular area of the hospital organization. From this perspective, the speaker suggests that knowledge exists as informal 'knowing' at an individual (personal) level rather than as that which has been formally integrated at the organizational level.

Finally, Liz concedes that despite having an 'openly lesbian' clinical coordinator lesbian concerns and/or issues are not "getting talked about in quite the same way" as the health needs of gay men. Again, suggesting that what is known by particular individuals at an informal level is not necessarily knowledge that has been consistently integrated within the organization.

An important finding that emerges from the analysis is the marginalization of lesbian voices in the knowledge production process. The speakers indirectly convey the notion that lesbian voices are 'pushed aside'. Ellen, for example, states that "issues haven't come forward very strongly, so uhm .... it's kind of hard to push it", and Liz acknowledges the difficulty of having concerns heard even in the context of an 'openly 
lesbian' coordinator. Finally, Frances' excerpt most clearly demonstrates this notion. When asked the source of the concerns raised Frances states: "from outside sources, in talking to, ah, women that are lesbians either who work here, who are coworkers of mine .. that is information that they've given to me." When lesbian experiences and realities are expressed they do not become a part of knowledge production but rather are relegated to 'scuttlebutt'. Conceivably, the speakers may not be experiencing discord but rather may be expressing the 'space' which exists the marginalized voices of lesbians.

The use of language in Frances' excerpt is of particular importance to this analysis, specifically the term 'scuttlebutt'. Francis's choice of the word 'scuttlebutt' functions to minimize and make invisible both the trauma of violence, and oppression as a result of having one's subjectivity incorrectly constructed. The speaker narrowly constructs lesbian sexual orientations in the context of 'absence' by submitting: “... when you're a gay woman there's no understanding of the fact that maybe this person isn't having sex with men ...". In this way, Frances defines lesbians in relation to the absence of men rather than in relation to the presence of women and, in doing so, constructs lesbian subjectivities as lacking. From this perspective, one could argue that even when organizational knowledge exists informally the concerns and/or issues of lesbian service users may not be addressed by organizational programs that continue to locate lesbian subjectivities within heterosexist practices. 


\section{Theme \# 2}

\section{Gay Men as a Vocal Community}

Community input was identified by all respondents as an integral part of the change process by which Organization $A$ became more responsive and welcoming to diverse communities. Community consultation and direction is established and maintained through the development of several advisory committees which provide 'space' for members of diverse communities and by which their voices can be heard. The research participants identify communities as defined by culture, medical diagnosis, socio-economic status, and sexual orientation. The following discussion will focus on participant responses in relation to the concerns and/or issues of lesbian services users.

The vocality of gay men as a community of service users was raised by three of the four research participants, despite being asked questions which specifically focused on organizational knowledge about the concerns and/or issues of lesbian service users. Participant responses suggest that a differential exists with respect to organizational knowledge about gay men as a community as compared to gay women as a community. The participants discuss the vocalness of gay men and the knowledge differential as related to both the HIV/AIDS crisis and the existing hierarchy of power based on gender, class, and race.

Frances clearly identifies the impact of the HIV/AIDS crisis on organizational knowledge production when submitting that: -men have really with AIDS taken their sort of .. the really forefront .. of, really pushed for .. been really vocal and really organized and so on and so forth ...". 
Frances elaborates on the organizational knowledge differential to include the larger sociopolitical context by submitting that:

Like men usually grab the headlines, grab the attention, women are always second kind of thing and I think it's been that way. My sense in the gay community, you know, again men are always up there front row centre and women are always sort of second to everything and that might be part of the reason why .. gay men's health has taken more of a front seat...

The speaker clearly implicates gender inequalities when explaining why more is known about the health concerns of gay men as compared to lesbians. Ellen enthusiastically reiterates this notion when responding to this researchers query about some of the barriers contronted by a group of women that unsuccessfully attempted to get the "hospital to address the needs of women who are lesbian". When asked "what do you think some of the barriers might have been?", Ellen responds:

-Uhm ... women (laugh), and the lack of the health profession to look at women as, you know, when you think of it just generically how all the, all the drugs are tested on men and, and, da .. da, the amount, you know, the fact that more women die of breast cancer than men die of AIDS and yet ... and I'm not saying, don't get me wrong, that there shouldn't be money for AIDS testing, and, and .. but, uh (laugh) it's pretty, ah, it's pretty obvious that ... as women we're not as important in the medical profession and we're not particularly important as members of society".

Ellen goes on to state that when you add being a lesbian on top of being a women "you just get knocked farther down".

Similarly, Liz identifies both the HIV/AIDS crisis and the larger socio-political context as factors implicated in the vocalness of gay men. Initially, Liz defines the "gay community" as a motivating factor for change in that it "challenged the hospital" to be more welcoming. 
However, Liz elaborates more directly and specifically when stating:

I don't know that some ethnic groups are as a powerful voice or as organized and the poor certainly don't, and the homeless don't so, that's probably THE most organized and vocal and powerful group in this community. Maybe not .. lesbians so much as, as, as gay men .. and AIDS certainly activated ... that, that, uhm, advocacy.

Finally, when describing the history of the hospital organization with respect to developing an awareness of homophobia, particularly, in response to community input Ellen clearly identifies the "very strong advocacy from (I would say) at that time the gay, gay men" as an influential factor in the change process.

It is important to acknowledge that the vocality of gay men is not understcod as being responsible for the 'voicelessness' of lesbians as a community of service users but rather is used to explain why the organization has more knowledge about the concerns and/or issues of gay men (as a community) than compared to lesbians (as a community). The analysis of participant responses indicate that speakers were more likely to relay organizational experiences and knowledge as related to gay men than to lesbians. This could be explained in that within a health care context knowledge will most directly be related to a health crisis, and gay men were those primarily (and initially) affected by HIV/AIDS. What is so deafening within this theme is the absence of information/knowledge/stories that relate specifically to lesbian service users and their health needs. It is not the vocality of gay men that is so alarming but rather that to be heard a community must exist within the context of a health crisis. Frances clearly demonstrates this notion when responding to this researcher's query about whether concerns have been raised by lesbian service users. Frances states: “Nope, there hasn't. I think, uhm, that maybe sometimes the squeaky wheel gets the grease and women haven't been as vocal". Conceivably, the 'squeaky wheel' was greased within the context of the HIV/AIDS crisis. 


\section{Theme \# 3}

\section{An Organizational Philosophy of Patient-Focused Care.}

The importance of a patient focused approach for meeting the needs of diverse client populations is emphasized by three of the four respondents as a general philosophy towards providing appropriate and sensitive care. A patient focused approach is understood by respondents as useful for recognizing individual needs based on diverse elements including culture, class, and sexual orientation as well as needs related to specific physical and medical conditions. Research participants discuss this philosophy in response to a broad range of topics such as initiatives addressing homophobia, the (sometimes) invisibility of lesbianism as a culture, and concerns and/or issues as identified by the lesbian community.

While discussing organizational initiatives that address homophobia Ellen describes an organizational "paradigm shift" in which care providers look beyond the medical diagnosis in order to meet the unique needs of clients. Ellen submits that -most people are trained to look at people as a disease or, or an illness or whatever .. you, you know, rather .. and, and who they are as an individual kind of gets lost in the context ${ }^{-}$.

Cheryl discusses the notion of patient focused care when asked about the potential for not identifying lesbian service users in light of the fact that they are often invisible or non-identifiable as compared to visible minorities. The speaker responds by describing an organizational concept of culture as invisible, and therefore, something that is not to be assumed based on that which can be observed, for example, skin colour and dress. Cheryl confidently identifies patient focused care as a strategy by which health care providers can avoid assuming to know client needs based on visible cues. From this perspective, a lesbian sexual orientation is viewed as an invisible culture, thereby suggesting that 
(hetero)sexuality is not assumed. The speaker emphasizes that avoiding assumptions about the concerns and/or needs of people means going back to "that one concept of patient focused, patient sensitive care, each person's a unique individual ..."

The philosophy of patient focused care is an important theme in light of the previous discussion which highlighted both the inconsistency of organizational knowledge and the lack of recognition for lesbians as a community of service users. Within this context a patient focused approach could be problematic in that health care providers may be "forced' to see lesbian service users as "individual" due to the lack of community 'context' by which to understand concerns and/or needs. From this perspective an individual, patient focused approach could reinforce lesbian invisibility, and, in doing so act to obscure rather than to explicate the concerns and/or issues of lesbians as a community of service users.

Some participants extend the general philosophy or paradigm shift of patient focused care to include the actual medical and physical needs of clients. Frances, for example, describes the organizations "real push" as making:

gay and lesbian patients feel that they can be themselves .. that they can be open about their sexuality .. IF IT'S RELATED .. maybe it doesn't relate to you, you know, if you've got a splinter in your foot it doesn't relate but, ah, if you had a gynecological problem if you're a women or if you are, you know have pneumonia if you're a gay man and you're concerned that you might have HIV...

When responding to an inquiry about organizational knowledge of the concerns and/or issues as identified by the lesbian community Cheryl reiterates the need for a focus on the individual as related to the client's physical and medical status by stating that:

you couldn't do it on a corporate, you can't say all lesbians have these needs, lesbians coming in to have a baby have certain other needs than lesbians coming in to Emerg for something else and, you know, that kind of approach. 
The concept of clients' needs as existing at an individual level addresses distribution of access rather than the experience of oppression. Cheryl's excerpt is indicative of such a notion; by focussing on lesbians as clients with different needs and utilizing different services Cheryl fails to address the socio-political context of the organization and its effect on lesbian service users regardless of need. One implication of focusing on the distribution of access is that in an attempt to meet the needs of lesbian clients the relevance of their experience based on their sexuality (diversity) or lesbian sexual orientation (uniqueness) is minimized or over specified. From this perspective, lesbian subjectivities may be constructed as fluctuating depending on the diagnosis/event/program. Subsequently, one could ask: when is a lesbian sexual orientation identified as related, and who decides this? Frances, clearly demonstrates this notion when submitting that gay and lesbian patients can be open about their sexuality "if it's related". Frances vocally emphasizes a "relational" notion between one's openness about sexuality and diagnosis by raising her voice when stating "if it's related"; Frances goes on to discuss stereotypical concerns of women (gynecological problems) and gay men (HIV/AIDS).

\section{Theme \# 4}

\section{Creating Change: Education and Staffing}

Education and staffing are identified by all respondents as necessary for knowledge production and change. The participants discuss educational and staffing measures in response to questions that explore existing barriers for lesbian service users, initiatives that look beyond HIV/AIDS in relation to lesbian service users, and policies that address diverse communities. Two important sub-themes emerged from the data; these include: (a) educational initiatives as existing policies; and, (b) hiring practices as existing policies 


\section{Educational Initiatives as Existing Policies}

Educational initiatives were developed in response to both community feedback of staff homophobia and a recognition by hospital administration that "hospital staff were very homophobic" and "needed homophobia training". Educational initiatives are sited by research participants as necessary to the change process; Liz highlights a formalized and "compulsory" organizational initiative that provided "anti-homophobic training" for all staff. Educational initiatives often appear to represent existing organizational and departmental policies as related to meeting the needs of diverse communities. Frances, for example, does not identify a policy when responding to this researchers inquiry about existing departmental policies but rather states "I think more than policies we had to develop some understanding so we did a lot of self-education ..."

When asked specifically about whether a policy and/or mission statement exists to address the health needs of lesbians, Cheryl directly states "not that I know of"; the speaker makes reference to the hospital mission statement as one that is "very broad" and that includes "access and diversity". Cheryl goes on to discuss educational initiatives including a strategy by which education is provided at the program level in relation to specific concerns and/or issues. In the area of domestic violence, for example, Cheryl identifies a need for education to learn that "it doesn't necessarily have to be a man and a woman when we're talking about domestic violence". Cheryl's uncertainty about the existence of organizational policies contrasts with her knowledge about educational initiatives; this analysis suggests that it is the latter that plays a more prominent role in guiding organizational practices.

Ellen's response to an inquiry about specific initiatives that address homophobia provides a richer and more explicit description of the relationship between education (as 
policy) and organizational practice. Ellen discusses the role of a community worker to provide one-on-one education within a departmental setting in an effort to raise staff consciousness about homophobia and discrimination by stating:

... in the (area of the hospital) .. specifically it was a lot of, of one on one talking or challenging, uhm when, uhm, there were incidence either reported or, or a in the role, one of the roles was to hang around the (area of the hospital) "cause some of this stuff is often hidden, so if you're around and kind of chatting with people informaily, uhm ... you get to hear things and you get to go to someone and say well, you know, that isn't the best, you know .... in, in a diplomatic way (laugh) we're often challenging in a way to not engender someone's anger 'cause sometimes it wasn't deliberate.

From this perspective, education serves the necessary function of uncovering assumptions that exist within organizational practices, and that may foster oppression by creating barriers for diverse communities of service users. Conceivably, educational initiatives represent the implementation of "broad" organizational policies such as the mission statement as previously discussed by Cheryl.

\section{Iliring Practices as Existing Policies}

The importance of educational initiatives for creating a more accepting and welcoming environment is clearly supported by the analysis of participant response. It also becomes evident from the transcripts that strategies other than education are required. More specifically, the analysis of participant responses suggest that the hiring of staff from diverse groups including lesbian and gay communities is integral to knowledge production and change. Liz, for example, within the context of discussing barriers that exist for lesbian service users, identifies the hiring of "a very assertive, aggressive bunch of people" as responsible for challenging assumptions around sexuality. Liz does not identify members of this group as lesbian (or gay), however, one might assume within the context of the question that lesbians or gay men constitute some portion. At another point, while 
discussing the process of change at Organization A Liz overtly identifies the hiring of lesbians and gay men:

So, staff expanded and uhm, as a result of that the kind of staff that they were hiring .. the staff became less homogeneous, they began to hire people who were, uhm ... I, I don't think I knew anybody in the hospital who was really out, uhm, in terms of gender orientation ... but it wasn't in to be out so, uhm, this changed, uhm, people got hired, people became blatantly out ...

Cheryl identifies the prevalence of "gay staff" by stating:

... there's a lot of people here that are openly gay, you know, both men and women, so .. gay and lesbian, uh, and it's not something that they feel they have to hide or they have to FLAUNT, it's just the way it is.

The language of the respondents suggest that, despite an organizational recognition of the value of hiring staff belonging to diverse groups - specifically, lesbians and gay men - underlying assumptions about the overt expression of sexuality persist. Liz and Cheryl each use language that constructs the expression of gay and lesbian sexual orientations as 'unnatural'. Liz, for example, refers to "people" as "blatantly out", whereas, Cheryl uses the word "flaunt" while trying to express a notion that lesbians and gay men are comfortable with their sexuality. Each of these terms suggest that there is a particular way that lesbians and gay men should express their sexuality; conceivably, not unlike the 'natural' way that heterosexuality is expressed.

Ellen discusses the hiring of lesbian and gay staff within a particular clinic that provides services to a large client population living with HIV/AIDS. Ellen submits that:

there's some staff that were hired specifically because of their skills, uhm, and uhm, the fact that they were gay and lesbian. Uhm, I wouldn't say it was deliberately factored in but it was kind of like a, a plus (laugh) in their hiring .

It appears that Ellen is saying that being lesbian or gay is indeed a specific skill for which people are hired, however, she retracts this with her second statement in an attempt to undo 
what might be considered an organizational 'unspoken'. Ellen laughs during her response in a way which suggests that she has just been 'caught'. The speaker appears hesitant to identify the purposive hiring of lesbians and gay men, although it is alluded that this is viewed as a successful strategy for change.

Conceivably, an organizational reliance on the hiring of diverse staff for knowledge production and change may be problematic in two ways. First, it presumes fixed identities and suggests that a 'truth' exists about categories of people. Second, it avoids the issue that staff and policies should meet the needs of all people, and that it is the responsibility of staff and the organization to educate themselves. From this perspective, the safety of lesbians during their health care interactions, for example, would not depend solely on receiving service from 'the' lesbian nurse. A consideration of the diversity of lesbian communities based on, for example, race, culture, and socioeconomic status presents a complex picture of attempting to provide 'sensitive' health care services through needspecific hiring.

The language used by Liz and Cheryl, and the hesitancy of Ellen to openly and comfortably identify the purposive hiring of lesbians and gay men: (a) suggest a possible 'cautiousness' on the part of the organization when (homo)sexuality is perceived as being overtly expressed or intentionally recognized; and, (b) conceivably, reflects the difficulty of revealing and changing the hidden values and assumptions that are embedded in, and that guide organizational policies and practices. 


\section{Organization B}

The cross-comparative data analysis method yielded a different yet parallel 'set' of themes from Organization B. The following section will include a presentation of the themes revealed from the transcripts with some comparison to those related to Organization A. The respondents from Organization B include: 'Anne', 'Wendy', 'Kathy', and, 'May'.

\section{Theme \# 1}

Organizational Knowledge of the Concerns/Issues of Lesbian Service Users.

All participants were asked questions about organizational knowledge and sensitivity to the concerns and/or issues of lesbians as a community of service users. Three of the four respondents identify an organizational need to understand and address the concerns and/or issues of lesbians, however, they do so with varying degrees of openness. This analysis suggests that the degree of openness of participant responses is reflected in the ways in which the questions are answered and, conceivably is reflective of the stage of organizational knowledge production. The forth respondent does not speak to the concerns of lesbian service users but rather draws on organizational experiences with HIV/AIDS.

When asked whether concerns or issues have been raised within specific committee, departmental or organizational settings Wendy apologetically states “No, no, no. It doesn't mean that it's not there it's just that I haven't heard it ..." Wendy goes on to discuss the need for "community reps" for hearing the concerns and/or issues of lesbians as well as some of the difficulty that she has experienced while trying to recruit 'overworked' representatives from lesbian and gay agencies and groups. Wendy provides a direct and honest view of organizational knowledge and sensitivity to the concerns and/or issues of lesbian service users while providing some insight into the stage of organizational 
knowledge production. That is, as a representative of a diversity committee Wendy's response indicates that unlike Organization A organizational knowledge is not being produced in an inconsistent way but rather is simply not being produced. From this perspective, Wendy is unable to refer me to another respondent or contact person who has knowledge of the concerns and/or issues of lesbians as a community of service users.

May directly and unapologetically recognizes a lack of organizational knowledge and sensitivity to the concerns and/or issues of lesbians when submitting:

I think that there's, uhm ...I the hospital, in (name of hospital) on the whole I think there's an enormous lack of awareness of the number of lesbians out there who need health care specific perhaps to their sexuality or their process of, you know, coming out or any number of issues.

May's response is reflective of her own understanding as a self-identified lesbian of the concerns and/or issues of lesbians as a community of service users within the context of Organization B. May's response is presented as more critical and conveys less of a feeling of responsibility than Wendy's response.

Anne characterizes organizational knowledge and sensitivity as an abstract understanding of "lesbian needs" rather than a concrete understanding of the specific concerns and/or issues of lesbians as a community of service users. Anne responds to an inquiry about whether concerns have been raised from the lesbian community(s) by stating:

Uhm .... certainly (name of program), the specific (name of program) here at (name of clinic), uhm ... I think they have, they have made a superb effort to acknowledge and, and, try to get the word out that, that ah, uhm, that we are aware of lesbian needs, uhm, we would .. if they would feel comfortable coming we'll try to meet their needs ...

Anne's response pattern is less open and direct than the responses of Wendy and May and is relevant in two ways. First, Anne does not answer the question - the speaker does not state (is unable to state?) whether or not concerns have been raised from the lesbian community(s) but rather redirects the question by talking about the program's position. 
Second, Anne's use of the words "if they would feel comfortable coming we'll try to meet their needs" suggests that the organization has done its part ( now it is up to lesbian communities), and functions to put the onus on lesbians for self-disclosure. This analysis supports an abstract recognition through organizational knowledge of the concerns and/or issues of lesbians and, conceivably supports the notion that organizational discussions of lesbian concerns and/or issues has been minimal.

When responding to the reframed question the speaker repeats this response pattern by redirecting the discussion. Anne submits:

Uhm ....... when, uhm, when we've gone out to talk, for example, uhm .. one of the students and I went out to the gay, lesbian, bisexual, uhm, hotline group, uhm, just to chat about what they saw were issues, uhm, they gave us a lot of good feedback that they, ah, they were pleased we'd come, really appreciated we'd come, they felt good about referring people here .. and uhm, se we, we certainly had this kind of dialogue which, which was, was excellent and, and also having people on our advisory committee we pick up if there's any, you know, if .. they're letting us know if somehow someone ran into a problem when they came, when they accessed our service.

Anne does not identify concrete concerns and/or issues but rather indicates a general knowing of the "problems" that lesbians may 'run into'. Again, an analysis of the speaker's response indicates a lack of organizational discussion (knowledge) about the concerns and/or issues of lesbians as a community of service users.

An analysis of Kathy's response to an inquiry about the concerns and/or issues of lesbian service users supports the notion that organizational knowledge and sensitivity is both minimal and abstract. Kathy is unable to draw upon organizational experiences with lesbian clients and instead provides a story about the experience of a male patient with HIV. Conceivably, Kathy dces not have direct organizational experience or knowledge to draw upon that would satisfy the requirements of the question. 
The respondents' views of organizational knowledge and sensitivity greatly vary and suggest that (a) organizational knowledge and sensitivity exists in a minimal and abstract way; and, (b) that Organization B, compared to Organization A, does not recognize an 'informal knowing' of the concerns and/or issues of lesbian service users.

\section{Theme \# 2}

\section{The Need for Community Consultation to Meet Community Needs.}

Three of the four participants from Organization B talk about community consultation as necessary for identifying and meeting the needs of people from diverse communities. Speakers identify community consultation in response to questions that explore both the experiences of the organization with respect to diversity, and factors that motivated organizational changes in philosophy. Despite, a recognized need for community input a relevant sub-theme emerged that indicates a lack of lesbian representation as both a community of service users and as members of organizational committees.

Community consultation is recognized as an effort by the organization to be "more open" through listening to clients and communities, and as necessary for knowledge production that is specific to diverse communities. Anne, for example, identifies a shift in the understanding of diversity as reliant upon community input that allows for the hospital organization to "reach out to the community, to ask the communities what their needs are". In this way, the hospital organization does not impose pre-defined problems and/or concerns but rather provides the space for communities to define their own concerns and solutions in partnership with the organization.

Similarly, Wendy responds to a general inquiry about organizational experiences of diversity and difference by recognizing the necessary role of community participation. 
Wendy states: "I think there's plenty of work to be done, you know, plenty of work .. we need as much community input as possible ..." And finally, Kathy identifies having "heard stories" of a specific community of service users as a necessary component for identifying their specific needs. Kathy states:

... we've listened to women for fifteen years, you know, you know what the story is, you don't have to do the research on it, you've heard what their concerns are, you've heard what their symptoms are, you know that they don't present the same way that men do and you know that they sure don't have the same concerns, you know, and uhm, it's, it's just being the type of people who listen to patients.

\section{The gap: leshians as a community of service users}

Research participants agree to the importance of community representation for identifying and meeting the needs of diverse communities, however, this analysis suggests a general lack of lesbian representation as both a community of service users and as members of organizational committees.

When asked directly about lesbian representation within a specific committee that addresses women's health issues Anne reluctantly identifies a gap in representation by stating:

Uhm, there's a representative from (name of agency which is not lesbian identified) .. uhm, ah .. and there's representation from, uhm .. uhm ... an East Indian woman.. who's on the committee ... uhm .. (name of agency) has been very good because they're a community group who's been, who's dealt with a large number of issues .. there isn't any specific person.

Anne proceeds by discussing barriers to accessing lesbian representation due to financial constraints of the organization and work schedules of potential members. In doing so, the speaker negates the need for lesbian representation by submitting:

... one of the things that, when there are specific issues we've gone out to consult with people and ask them for input on specific issues as, and, and bring that back to, ah, to the group. 
The analysis of Anne's response raises two important questions which are related to community representation and the identification of lesbian concerns and/or issues. First. who defines the "specific issues" in the absence of lesbian representation; and, second who represents the lesbian community(s) during the consultation process?

Wendy discusses the lack of lesbian representation in response to questions about an organizational committee that addresses diversity, and which is comprised of employees, only (in-house organizational committee). When asked whether issues around sexual orientation have been raised within the context of the organizational committee Wendy willingly acknowledges the difficulty of recruiting "people of this orientation" due to the fact that people "don't identify themselves" because of barriers and stigma. Of particular importance to this analysis are the implications for staff and service users due to the barriers and stigma, but, these implications are not addressed. This is problematic in that ignoring structural barriers and stigma shifts the onus on staff to self-disclose rather than addressing it as an organizational (structural) issue. Conceivably, the inability to recruit representatives could be indicative of the level of organizational openness, knowledge and sensitivity to the concerns and/or issues of lesbians as employees as well as service users. Wendy does identify one member of a second diversity committee comprised of community members as lesbian, however, this committee is in its infancy and, at the time of the interview has provided minimal feedback to organizational representatives (the Board of Directors). 


\section{Theme \#3}

\section{Education as a Means of Change}

Education is identified by all participants as a necessary part of creating change through an increased awareness and understanding of diversity and difference. Participants discuss the need for both formal and informal education at the individual and organizational levels in an effort to challenge assumptions and beliefs related to sexuality.

Anne talks about the need for education in response to this researcher's question about whether lesbian concerns or issues have been raised within the organization or within individual clinics/programs. Although, Anne does not answer the question directly she provides some insight into the process of informal education at the individual level. Anne confidently states that "if something happens that we feel somebody was denied service or, or some, ah, discriminatory remark was made we try then to educate people ..."

May clearly identifies part of her role as increasing the awareness and sensitivity of other employees to the concerns and/or issues of lesbian service users. May submits:

I certainly raised, uhm, the awareness in so far as we did have certainly lesbians who were (clients of a particular clinic), uhm, bringing that up in meetings, ah, talking about outreach, uhm .. are lesbians ... closeted in regard to health care because we aren't making ourselves acceptable to them .. by having a, you know, sort of an outreach, ah, program or philosophy.

When asked how diversity is addressed Kathy discusses the role of educators as "key people in the institution who have been addressing cultural diversity". Kathy identifies the multicultural focus of a clinical nurse specialist by describing her role as someone who looks "after some basic things like interpreter services and stuff like that, also heavy on the education, I mean, lots of, uhm, VERY multicultural education ..."

Wendy discusses the educational role of the organization as extending beyond the boundaries of the institution to include the local community. Wendy refers to a lecture 
series which is open to "everybody": "It's not just the hospital staff, so anybody interested, especially, ah, agencies out there and hospitals, and so we, we do send out information about education sessions to them".

The analysis of participant responses suggest that educational initiatives related to the concerns and/or issues of lesbians appear to exist at an informal level, and within the context of one-to-one discussions or staff meetings whereas educational initiatives at an orgarizational level appear to be related to multicultural issues. Conceivably, this is reflective of a lack of organizational discussion and knowledge of lesbians as a community service users.

\section{Themes and Patterns as Interrelated}

Through the process of the cross-comparative and discourse analysis the interrelatedness of the themes from Organization A and B, and their connectedness to the conceptual framework presented in Chapter One became evident. That is, identifying the unitary themes uncovered how they work together to perpetuate the assumption of heterosexuality and to influence lesbian (in)visibility. If the words of the speakers represent organizational policies and practices, as loosely defined, then the same words give rise to the implications of these findings. This will be further explored in the following chapter. 


\section{CHAPTER FOUR}

\section{Discussion}

But, I think in .. the bottom line .. there hasn't really been a lot that's specific to lesbians. I think it's pretty much, uhm .... what's happened for lesbians as - is a result of what's happened for gay men.

"Ellen", a participant

This section will explore the findings related to Organization A and Organization B. The purpose of this discussion is two-fold; first, it will highlight the 'interrelatedness' of the themes from the organizations. Second, it will link the findings to the conceptual framework presented in Chapter Two. In this way, the findings will be analyzed in relation to individualizing and normalizing practices (objectification), and subsequently, the assumption of heterosexuality, and the (in) visibility of lesbians as a community of service users. I will conclude by discussing the implications of the findings including an examination of the strategies which social workers within hospital organizations could use to resist practices that facilitate and maintain the assumption of heterosexuality and lesbian invisibility.

Prior to this discussion I will address the issue of 'richness' and 'description' with respect to the data. An overarching 'finding' that emerged from the data analysis process is the contrast in both 'richness' and 'description' as indicated by the transcripts from each organization. Unlike Organization A, the transcripts from Organization B lack both depth and extensiveness. That is, from this researchers perspective compared to Organization A: (a) research participants, from Organization B, were less likely to stray from their 
'organizational locations' and, therefore presented as more cautious; conversations seemed less open and direct (with the exception of May who spoke more from her location as a lesbian); (b) there is consistently less content about lesbian service users in the interview transcripts from Organization B; there was minimal 'space' to discuss organizational experiences related to lesbian service users. Conceivably, this reflects the stage of organizational knowledge production about the concern and/or issues, and the lack of organizational recognition and experience.; (c) the history of recognizing the concerns and/or issues based on organizational experiences with HIV/AIDs and the health needs of gay men as well as its work with diverse communities is not as established within Organization B; and, (d) speakers from Organization B did not convey the concerns of lesbian and gay communities as a political issue within the context of change.

The following discussion will explore the findings as related to knowledge production, the construction of lesbian subjectivities, and strategies for change. I will argue that the analysis supports the notion that within Organization A and Organization B lesbians as a community of service users experience fleeting visibility and invisibility, respectively; and, that this phenomenon is largely a result of practices which individualize lesbians and normalize heterosexuality. I will suggest that individualizing and normalizing practices do not exist as distinctly identifiable but rather are a function of the interrelatedness of the themes as earlier presented. In an effort to fairly represent both the speakers and the unique characteristics of the hospitals each organization will be examined independently.

The findings that emerged from the data of Organization A reveal that (a) organizational knowledge of the concerns and/or issues of lesbians as a community of service users is inconsistent between departmental settings, and that informal knowledge is not formally integrated into the organizational structure; (b) lesbians are not represented as a 
community of service users. Consequently, knowledge production occurs in the absence of a formal recognition of lesbians as a community(s), and therefore, without community input. From this perspective, the experience (collective voice) of lesbians as a community of service users remains silent, or is marginalized within the discourse. Other important findings include (c) sexuality is defined as relevant in relation to diagnosis/medical concern; (d) lesbian sexual orientations are conceptualized at an individual level or rather as a private experience. The visibility of gay women is dependent on a 'relevant' medical concern (ie. pregnancy, physical injury due to gay bashing). From this perspective, the visibility of lesbian subjectivities is fleeting, and knowledge production functions to address the allocation and distribution of access. This ignores the socio-political environment of knowledge production and obscures significant harms to lesbian service users as a result of the (mis)construction of subjectivities (oppression).

The cross-comparative data analysis method revealed the following findings from Organization B: (a) a lack of concrete and formal organizational knowledge about the concerns and/or issues of lesbian service users - there is an abstract acknowledgment of 'lesbian needs'; (b) a recognized need for community input in the absence of formal lesbian representation; and (c) minimal educational initiatives on homophobia/lesbian service users. Similar to Organization A, the findings from Organization B support the notion that knowledge is produced in the absence of the collective lesbian 'voice' and ignores the sociopolitical context of health care delivery. Participant responses suggest that lesbian participation in organizational knowledge production is not the norm; lesbians are consulted if 'problems arise'.

These findings constitute normalizing and individualizing practices in that the experiences of lesbians is not recognized nor are lesbian communities formally affordedthe 
'space' to engage in knowledge production. From this perspective, heterosexuality is maintained as the 'norm' through knowledge production and lesbian subjectivities are constructed as existing within the private world of women, and thereby, are marginalized and individualized. A focus on 'lesbian needs' rather than the socio-political structure functions to privatize/individualize the experiences/reality of lesbian service users.

The question may be asked: how does social work fit into this exploration and understanding of assumed heterosexuality, lesbian invisibility, and lesbian health needs? The determinants of health are not only biological processes but also include the effects of financial need, inadequate housing, unemployment, inadequate social and emotional support, discrimination, and interpersonal relationships. Social workers within health care institutions and communities will work with lesbian clients around these issues. The discourses that inform social workers foster an assumption of heterosexuality and lesbian invisibility; as 'agents of social change', social workers have an ethical responsibility to examine those practices that silence our clients and create inegalitarian relationships.

\section{Strategies for Social Work Practice}

Sands and Nuccio (1992) assert that deconstruction involves analyzing discourse in "relation to social, historical, and political contexts" (p.491). This process 'decentres' dominant discourses while simultaneously 'centring' those that are marginalized (Sands \& Nuccio, 1992). 'Specificity' and 'oppositional positionality' are strategies that could assist social workers engaged in deconstruction of discourses within organizations. The use of such strategies could act to 'decentre' dominant discourses on lesbianism (which stabilize heterosexual hegemony/assumed heterosexuality) and to 'centre' marginalized discourses that construct lesbian visibility. By adopting these positions social workers could resist and 
work towards transforming institutional practices that exclude and silence lesbian clients. The goal of the strategies is not to reformulate 'the' discourse on lesbianism, but rather to provide social workers with a tool by which they can expose the power that lies within discursive practices.

\section{Specificity and Difference}

Phelan (1991) asserts that any effort to construct a singular concept will inevitably exclude "the lives of those who do not have hegemonic power of description." (p.130). This can be seen in the earlier examination of lesbian invisibility as a function of heterosexual hegemony (assumed heterosexuality) within health care settings. Discourses used by service providers to construct all women as heterosexual act as a blind behind which lie the experiences and realities of lesbian lives. Heterosexual hegemony ensures that heterosexist institutional practices remain unexamined and that assumed heterosexuality thrives. Phelan (1991) argues that by maintaining specificity through "categorical reference" (p.136) and by recognizing our "locations in various systems of power" (p.133), we can resist grand theories of subjectivities. Phelan (1991) argues for the use of specificity as a strategy for destroying hegemony.

Specificity, as a strategy of resistance, is relevant to social work practice in two ways. First, it is useful for recognising that we, as social workers, are located at "the intersection of various discourses and structures" (Phelan, 1991, p.136), and that we make claims based on these positions. This recognition would allow us to evaluate the knowledge that we produce from our various positions and perspectives. This would include, for example, evaluating the knowledge we produce about women's (hetero)sexuality. Second, specificity recognises the individual within the category. In this 
way, the individual subjectivity of lesbian clients would not be reduced to that of the constructed category of 'lesbian'. I will draw on one of my practice experiences to clarify these thoughts.

I met a woman within a hospital setting to provide supportive counselling around her decision to abort her fetus. In the course of our meeting she indicated that she was a lesbian. She was living with a man (who knew she was a lesbian) who provided financial support which allowed her to work at her art career without any financial worries. This was an arrangement upon which both she and this man had agreed. She did not appear distressed by or coerced into the relationship; she was open and honest about her interest in maintaining it. She had a female lover. My intervention included an assessment of social supports, her feelings around her pregnancy/the abortion, and information on birth control and safe sex (routine).

I discussed this case with a co-worker as a means of highlighting the need for expectations of difference and diversity in the course of our 'social work'. The conversation quickly shifted to questions of how a lesbian 'gets pregnant' -- 'is she really a lesbian?' and 'she must be confused about her sexuality/not coping with her lesbianism'. These questions are products of discursive practices that construct all women as innately heterosexual, lesbianism as problematic, and heterosexuality and homosexuality as binary terms and fixed expressions of sexuality. The client came to be constructed by this worker as a deviant 'Other' in that she did not fit into the assumed category of female heterosexuality and 'unhealthy' in that she did not fit into the category of 'lesbian' in terms of an integrated identity. The worker reconstructed the client based on her own position as a producer of knowledge/power. She could not see the 'individual' client within the categories of '(heterosexual) woman' and 'lesbian'. This constitutes heterosexual 
hegemonic power in that the client's (woman's) voice (reality) was silenced by the workers reconstruction as a result of homophobic discourse and her position of power.

Social workers could use specificity to recognize that their knowledge/power exists within heterosexist institutional discourses as well as to create space for difference and diversity between and within categories. These actions constitute a form of resistance to and transformation of homophobic discursive practices that inform social work practice.

\section{Oppositional Positionality}

Social workers rely on the social work values of 'acceptance' and 'non-judgmental' attitudes, for example, to guide egalitarian relationships with clients. These values present themselves as 'ideals' which social workers are expected to internalize, and by which they see and address injustices. Social workers produce knowledge about clients and their oppression based on this subjective 'value laden' stance. Unfortunately, these values do not help us to analyze critically our social work practice or organisational practice. By choosing to adopt positions of opposition or marginality within their organizations social workers as 'agents of social change' could resist discursive practices that deprive lesbian clients of their own voice. This approach could be particularly relevant to social workers, especially lesbian and gay social workers, employed within hierarchically structured organizations such as hospitals.

Halperin (1995) describes oppositional positionality as a means by which 'Others' may speak for themselves as a 'collective discourse'. Traditionally, movements within lesbian and gay communities have fought against discursive practices that have sought to construct and objectify 'the' homosexual. One way in which this has been accomplished is by reversing the respective positions of homosexuality and heterosexuality, that is, by 
shifting "heterosexuality from the position of universal subject of discourse to an object of interrogation and critique, and to shift homosexuality from the position of an object of power/knowledge to a position of legitimate subjective agency" (Halperin, 1995, p.57).

This reversal is evident in the gay movement's recapitulation of the medical discourse on homosexuality (Halperin, 1995). Contemporary struggles within gay and lesbian communities posit homosexuality as natural in that 'we are not gay by choice'. In this assertion and as subjects of knowledge, lesbians and gay men recycle the categories of medical discourse, specifically, the naturalised and binary terms of heterosexuality/homosexuality (Halperin, 1995). This approach constitutes an act of resistance in that the terms are recapitulated in an affirmative way. The aim of this resistance is not necessarily to "reconstitute homosexuality as a real object to be studied" (Halperin, 1995, p.60), but rather to treat homosexuality as "a potentially privileged site for the criticism and analysis of cultural discourses." (Halperin, 1995, p.60). bell hooks (1990) discusses this strategy as a means of recognizing marginality not simply as a position of deprivation but also as one of resistance. In this way, oppositional positionality or marginality is not something one strives to 'leave behind' but rather it becomes "a site one clings to because it nourishes one's capacity to resist"(hooks, 1990, p.150).

hooks (1990) states that "to be in the margin is to be part of the whole but outside the main body" (p.149). This works as an advantage, in that those in marginalized positions "look both from the outside in and from the inside out" (hooks, 1990, p.149) and, in doing so, develop an understanding of both the margin and the centre. This provides a location for the production of counter-hegemonic discourse: a location that cannot be experienced by those who choose to remain in 'the centre'. One question may arise from this discussion: must one be marginalized at a personal level to assume an 
oppositional position within an organization? No, social workers, as 'agents of social change' employed within lateral hierarchical power structures that value 'objective' and 'scientific' knowledge (such as those employed within hospital settings) likely already occupy marginalized positions as imposed by such an oppressive structure. By accepting their position as marginalized social workers could resist producing knowledge from a subjective position of 'knowing' (from the centre): a position of authority and control and, in doing so, could use their position to produce counter-hegemonic discourses.

Social workers, from their marginalized positions within health care settings, could act as a link between the knowledge produced by those in the centre and the realities of 'Others' existing in the margin. In the area of obstetrics and lesbian pregnancy, for example, social workers could resist discourses that construct heterosexual intercourse as 'the' norm for producing pregnancy. This could be accomplished by deconstructing the language used to describe alternate ways of becoming pregnant. The term artificial insemination', for example, highlights the power of language to reflect and define norms in that it suggests that pregnancies resulting from methods other than (hetero)sexual intercourse are unnatural. Moreover, this term speaks more to the experience of the medical profession than to the experience of women in that it refers primarily to a medical procedure. Social workers could advocate for language that is more reflective of women's experiences and that resists constructing a 'norm'. 'Altemative fertilization', for example. might to be used to describe the many ways that women can choose to become pregnant as well as a process of woman-controlled conception (Lesbian Health Matters!). In this way, social workers could create a forum in which the voice of lesbian 'Others' would be expressed and heard, thereby facilitating lesbian visibility. 
Oppositional positionality is also applicable to the practice experience described previously within the context of 'specificity'. My own history of being marginalized as a lesbian both at a social level and employment level places me in a position that allows for opportunities of difference and diversity. My experience of marginality allowed me to resist constructing the client (woman) as 'deviant' or 'unhealthy' through the use of dominant, homophobic discourse. I was able to resist overriding this women's own expression of her experience and reality.

\section{CONCLUSION}

Discursive practices within Organization A and Organization B continue to construct heterosexuality and homosexuality as binary opposites. The issue of dichotomous thinking throughout the institutions in relation to (heter/homo) sexuality remains an invisible factor which functions to perpetuate two separate discourses; one discourse on lesbian women and one discourse on heterosexual women. This is most evident in the policies and practices which normalize heterosexuality and individualize lesbianism including, for example, knowledge production as program driven, the focus of each organization on service access, and the failure of each organization to formally recognize lesbians as a community of service users. The organizational discourse based on the research findings

constructs lesbian sexual orientations (a) in the absence of a male partner rather than in the presence of a female partner; lesbians are therefore constructed as lacking; and, (b) as fleetingly relevant.

The implications for lesbian service users based on this construction and as related to the literature review of lesbian health care experiences presented in Chapter One means that (a) female heterosexuality continues to be assumed; (b) in consideration of the two 
separate discourses the onus would remain with lesbians to disclose their orientation or to 'out' themselves; (c) health issues related specifically to lesbian sexuality, for example, the transmission of sexually transmitted diseases between women is not addressed (researched); (d) expectations or standards of inclusivity/visibility vary within health care settings; and, (e) lesbian service users are still required to 'guess' or 'investigate' which areas of health care are inclusive, and therefore, must continually negotiate their safety.

Gay women face risks due to organizational discourses that maintain lesbian invisibility, and that reconstruct the "lesbian' as "Other". The assumption of heterosexuality as indicated by the policies and practices within the hospital organizations studied symbolizes the reproduction of assumed heterosexuality as experienced by lesbians within the broader social context. Health care institutions must effect change by looking beyond that of individual health care providers. Rather, change must include an analysis of how knowledge production reproduces or perpetuates an assumption of heterosexuality within local hospital organizations. This would include exploring and understanding who is included in the process of knowledge production and how knowledge is dispersed and assigned within health care settings. 


\section{APPENI)IX A \\ INTERVIEW SCHEDULE}

\section{INTRODUCTION*}

- Who am I (interviewer).

Introduce myself and my affiliation. Inform interviewee that I am under the supervision of Dr. Pat Evans.

- $\quad$ Purpose of study.

Share the purpose of the study with the interviewee.

- $\quad$ Explain why interviewee was selected for participation.

- Confidentiality, audio taping, and right to discontinue participation at any time. Describe 'confidentiality' and reason for audio taping. Explain consent forms; sign forms.

- Do you have any questions before we get started?

\section{INTERVIEW QUESTIONS (administrative level)**}

How many beds are there at (name of hospital)? ** (background/demographic)

What type of out patient services/clinics does (name of hospital) provide? ** (background/demographic)

Does (name of hospital) have a "speciality area"? ** (background/demographic)

What is the catchment area for (name of hospital)? ** (background/demographic)

Does (name of hospital) have a religious affiliation? ** (background/demographic)

What is your position at (name of hospital)? ** (behavioral/experience)

What responsibilities does this position entail? ** (behavioral/experience)

Could you describe to me the policies that are in place at (name of hospital) regarding patient care services? (knowledge)

How do these policies address diversity or 'difference' with regards to the patient population/demographics using the services of this hospital? (knowledge) 
Appendix A cont ...

(If, yes):

Could you describe to me the circumstances that led to the development of this policy? (knowledge)

Did the policy develop in response to the experiences of one specific community of people? (knowledge)

Who was involved in the policy development? (knowledge)

Were community representatives involved in the policy development? (knowledge)

How was the policy implemented? (knowledge)

Has the implementation been completed/successful? (knowledge)

(If, no):

Has the issue of diversity or 'difference' ever been raised as a concern among your patient population? (knowledge)

How was this addressed? (knowledge)

Has the issue of diversity or 'difference' ever been raised as a concern among hospital staff? (knowledge)

How was this addressed? (knowledge)

\section{(Lesbian/Homophobia Specific):}

Have the concerns of lesbian patients/service users ever been raised among your patient population? (knowledge)

How was this addressed?

Have the concerns of lesbian patients/service users ever been raised among hospital staff? (knowledge)

How was this addressed? (knowledge)

Have the concerns of lesbian patients/service users ever been raised within this administrative department? (knowledge)

How was this addressed? (knowledge) 
Appendix A cont ...

\section{INTERVIEW QUESTIONS (departmental level)}

All interview questions for clinical leaders in the social work department will be stated as above except for those with asterisks. The following additional questions will be included in the interview schedule for clinical leaders. The word 'patient' will be replaced with the word 'client' for all questions.

How many social workers are employed within the social work department? (background/demographic)

What areas of the hospital does social work provide services? (background/demographic)

What is your position within the social work department? (background/demographic)

What responsibilities does this position entail? (background/demographic)

\section{Closing ***}

- Reminder of confidentiality.

- $\quad$ Reminder that the interview will be used only for the purpose of this research study.

- Offer to provide a copy of the completed thesis.

- Thank you!

* Introduction format will be the same for all respondents.

** These questions will be replaced by department -specific questions in the interview schedule for respondents at the departmental (social work) level.

*** Closing will be the same for all respondents. 


\section{APPENDIX B \\ INTER VIEW GUIDE}

\section{INTRODUCTION}

- Who I am (interview).

Introduce myself and my affiliation. Inform interviewee that I am under the supervision of Dr. Pat Evans.

- $\quad$ Purpose of study.

Share the purpose of the study with the interviewee.

- Confidentiality, audio taping, and the right to discontinue participation at any time. Describe 'confidentiality' and reason for audio taping. Explain consent forms; sign forms.

- Do you have any questions before we get started?

\section{INTERVIEW CATEGORIES (practitioner participant)}

- $\quad$ Employment/position related questions.

Number of years in the field of social work.

Number of years employed by hospital.

Area of practice.

- Client population related questions.

Describe client population.

- Experiences of client diversity or 'difference', ie., race, culture, religion, sexual orientation.

- Knowledge of hospital policy re: patient/client care services.

- Knowledge of departmental policy re: patient/client care services.

- Understanding of the issue of diversity or 'difference' as it affects intervention with clients re: organizational practices.

- Experience with clients around issue of sexual orientation; lesbianism/lesbian clients re: organizational practices.

- Understanding of usefulness of a policy that addresses diversity or 'difference', and the affects of implementation on organizational practices.

- Role of social work as a profession and as a department re: facilitating or advocating for organizational policy development. 
Appendix B cont ...

\section{CI.OSING}

- Reminder of confidentiality.

- Reminder that the interview will be used only for the purpose of this research study.

- Offer to provide a copy of the completed thesis.

- Thank you! 


\section{APPENDIX C FOLI.OW-UP LETTER}

(name of research participant),

I am writing following our telephone conversation on (date) to request your participation in research that I am undertaking as a student of the Graduate Social Work Program at York University. I am currently completing the first year of this two-year, part-time program. The research that I am undertaking is a component of my Master's thesis under the supervision of Dr. Pat Evans. Dr. Evans may be contacted at (416) 736-5329.

In the course of my thesis work I am interested in exploring hospital policies and practices with respect to diversity and difference. Particularly, I am interested in learning how (name of hospital) has recognized diversity and difference among its client population, and how this recognition has influenced patient care services.

I understand that the area of diversity and difference can be expansive and complex, and that health care facilities have demonstrated creative ways of meeting the needs of culturally diverse service users. A part of diversity and difference that may not always be as recognizable as culture is that of sexual orientation. I am particularly interested in learning about (name of hospital) experience with concerns or issues as related to lesbian service users.

This exploration would involve two aspects of study. First, it would require meeting with you to discuss organizational (departmental) policies and/or concerns related to this issue. Second, I would like to meet with one social worker to learn about his or her experiences with lesbian clients. Confidentiality will be maintained throughout the research process. Participants may withdraw their involvement at any time during the research process.

I will employ an open-ended, face-to-face interview technique with regards to departmental and organizational policies as well as with respect to social workers' experiences.

I have enclosed my resume to provide information about my educational and employment experience. I appreciate your cooperation and look forward to meeting with you to further discuss this research endeavour. I may be contacted at (416) 469-5051.

Sincerely,

Andrea Daley, B.S.W. 


\section{APPENDIX D \\ RESUME}

\section{ANDREA DALEY}

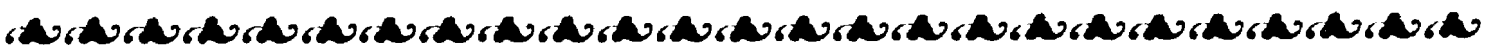

33 Robbins Avenue

Toronto, Ontario

M4I, $1 \times 1$

Telephone: $(+16)$ \$69-505I

\section{EDUCATION}

Sept. 1996 - Graduate Program in Social Work

Present York University, Toronto

1995 Bachelor of Social Work, Honours

York University, Toronto

1993 Bachelor of Arts, Psychology

York University, Toronto

\section{EMPLOYMENT IISTORY}

Mar. 1997 - Residential Counsellor - Relief

Present Rendu House, Toronto

- Provide supportive and referral services to women in need of emergency and temporary housing.

- Work as part of the staff team to perform intake, reviews, and to facilitate women's self- determination with regards to their day-to-day needs, and housing and employment goals.

- Assess and respond to crisis situations including consumer/survivor issues, addiction, and in-house conflict among residents.

June 1996 - Health Educator: Pre-Dialysis Project

Present Culture, Community, and Health Studies

Clarke Institute of Psychiatry, Toronto

- $\quad$ Provide motivating educational sessions and on-going support to pre-dialysis patients living with kidney disease.

- facilitate communication between clients, health teams, and social support resources to ensure that all client needs are addressed effectively. 


\section{Appendix D cont ...}

Feb. 1995 - Social Worker: Childbearing Services/Diabetes Education Mar. 1996 Doctors Hospital,Toronto

- Assessed clients pre and postnatal needs and implemented comprehensive plans to reduce psychosocial risks. Assisted teen mothers, immigrant and refugee women, low-income women and their families by developing individualized referral networks to address financial, settleent, social support, and housing needs.

- coordinated and advocated for individualized discharge plans to ensure medical and social safety nets for clients, including those who did not have health insurance; organized on-going care through community health centres for women and newborns

- $\quad$ assisted abused women and their children by utilizing refined crisis management and supportive counselling skills to develop safety plans, and to secure shelter services.

- $\quad$ Reduced risks for clients by promoting understanding about the psychosocial concerns for clients living with chronic and terminal illnesses; devised and delivered an in-service to clinic staff by utilizing real life situations to stress the effects of denial, anger, depression and everyday coping.

- facilitated client support groups and promoted mutual supportiveness and cohesiveness among clients through the shared experience of living with diabetes.

- $\quad$ assisted clients and their families by utilizing strong supportive counselling skills to encourage communication on the impact of chronic and terminal illness on family relationships.

- developed a comprehensive referral network to assist clients with financial needs for medication costs, and successfully advocated for special needs eligibility with income maintenance programs.

\section{VOLUNTEER WORK EXPERIENCE}

1996 Canadian Mental Health Association: Rehabilitation Action Program Provide on-going one-to-one support to a R.A.P. participant coping with consumer/survivor issues.

1995 Independent Study: Lesbians, Cancer, and Social Support Researched and developed a questionnaire research survey to assess the availability of support services for lesbians coping with cancer and/or the loss of a partner.

1994 Palliative Care Unit, Toronto Grace Hospital Facilitated additional patient and family care by providing emotional support and accompanying patients to social events and outside appointments.

1991 Research Assistant: Chronic Fatigue Study Assisted a professor with the development and implementation of a research questionnaire on the emotional and psychosocial experiences of living with Chronic Fatigue Syndrome.

1989 Planned Parenthood Counsellor Training Counsellor Training Program to provide information and support to women with respect to contraception, abortion services, and pregnancy concerns. 


\section{APPENDIX $\mathrm{E}$ PARTICIPANT INFORMED CONSENT}

This study explores hospital policy and practice to determine whether they reflect an assumption of heterosexuality, and the needs of lesbian service users. This study is conducted as part of the requirements of the Graduate Program in Social Work at York University under the supervision of Dr. Pat Evans.

I agree to participate in an interview about one hour in length in which I will be asked questions concerning hospital (departmental) policy and practice.

I understand that the interview will be audiotaped and I hereby give consent for audiotaping. I have been informed that the audiotape will be transcribed into typed form and that the audiotape will be erased once transcription is complete.

I have been told that all the information I give will be confidential. I understand that the information will be used only for the purpose of this research study. I also understand that I may contact Dr. Grant Macdonald, Graduate Program Director in Social Work, (416) 7365226 or Dr. Pat Evans, thesis supervisor, (416) 736-5329, for answers to questions or concerns.

I have been informed that the interviewer will be happy to answer any questions or to address any concerns.

I am fully aware of the nature and extent of my participation in this research project as stated above and the possible risks from it. I hereby agree to participate in this project. I acknowledge that I have received a copy of this consent statement.

Signature of Participant

Date

Printed Name of Participant

Interviewer's Signature 


\section{References}

Danziger, M. (1995). Policy analysis postmodernized: Some political and pedagogical ramifications. Policy Studies Joumal, 23 (3), 435-450.

Denenberg, R . (1992). Invisible women: Lesbians and health care. Health/PAC Bulletin, Spring, 14-21.

Douglas, C. (1990). Love and politics: Radical feminist and lesbian theories (pp. 156-184). San Francisco, CA: ISM Press, inc.

Eliason, M. (1996). Who cares: Institutional barriers to health care for lesbian, gay, and bisexual persons. New York, N.Y: National League for Nursing Press.

Epstein, S. (1987). Gay politics, ethnic identity: The limits of social construction. Socialist Review, 17 (3-4), 9-54.

Featherstone, B. \& Fawcett, B. (1994). Oh no! Not more isms: Feminism, postmodernism. poststructrualism and social work education. Paper presented at the 27th IASSW Congress. Amsterdam.

Gatens, M. (1992). Power, bodies, difference. In M. Barrett \& A. Phillips (Eds.), Destabilizing theory: Contemporary feminist debates (pp. 120-137). Stanford, CA: Stanford University Press.

Gentry, S. (1992). Caring for lesbians in a homophobic society. Health Care for Women International, 13, 173-180.

Greene, J. (1994). Qualitative program evaluation: practice and promise. In N.K. Denzin \& Y.S. Lincoln (Eds.), Handbook of qualitative research. Thousand Oaks, CA: Sage Publications, Inc.

Guba, E. \& Lincoln, Y. (1994). Competing paradigms in qualitative research. In D. Lincoln (Ed.), Handbook of qualitative research . London, GB: Sage Publications, Inc.

Halperin, D. (1995). Saint Foucault: Towards a gay hagiograpghy (pp. 3-125). New York, N.Y: Oxford University Press.

Hawkesworth, M.E. (1988). Theoretical issues in policy analysis. Albany, N.Y: State University of New York Press.

Hidalgo, H., Peterson, T.L. \& Woodman, N.J. (1985). Glossary (pp7-10). In H. Hidalgo, T. Peterson \& N. Woodman (Eds.), Lesbian and gay issues: A resource manual for social workers. Silver Spring, MA: National Association of Social Workers. 
hooks, b. (1990). Yearning: race, gender, and cultural politics (pp. 145-153). Toronto, ON: Between the Lines.

Kinsman, G. (1996). The regulation of desire: Homo and heter sexualities. Cheektowaga, NY: Black Rose Books LTD.

Kitzinger, C. (1987). The social construction of lesbianism. London, UK: SAGE Publications, Inc.

Marshall, H. (1994). Discourse analysis in an occupational context. In C. Cassell \& G. Symon, Qualitative methods in organizational research; a practical guide (pp. 91-106). Thousand Oaks, CA: SAGE Publication, Ltd.

Marshall, C. \& Rossman, G. (1995). Designing qualitative research (2nd Ed.). London, GB: Sage Publications Inc.

Maykut, P. \& Moorehouse, R. (1994). Beginning qualitative research; A philosophical and practical guide. London, GB: The Farmer Press.

Neuman, L. (1977). Social research methods: qualitative and quantitative approaches. Needham Heights, MA: A Viacom Company.

Nye, C. (1994). Discourse analysis methods and clinical research: A single case study. In E. Sherman \& W. Reid (Eds.), Qualitative methods in social work research (pp217-227).

Paris, D. \& Reynolds, J. (1983). Logic of policy inquiry. New York, N.Y: Longman, Inc.

Patton, M.Q. (1990). Qualitative evaluation and reseach methods (2nd Ed.). Beverly Hills, CA: Sage.

Peteros, K. \& Miller, F. (1988). Lesbian health in a straight world. In N. Worcester \& M. Whatley (Eds), Women's health: Readings on social, economic and political issues. Dubuque, IOWA: Kendall Hunt Publishing Company.

Peters, M. \& Marshall, J. (1993). Educational policy analysis and the politics of interpretation: the search for a well-defined problem. Evaluation Review, 17 (3), 310-330.

Phelan, S. (1989). Identity politics, lesbian feminism and the limits of community (pp. 37-80) (pp. 135-151). Philadelphia, PA: Temple University Press.

Phelan, S. (1991). Specificity: Beyond equality and difference. Differences: A Journal of Feminist Cultural Studies, 3 (1), 128-143.

Ponse, B, (1978). Identities in the lesbian world: The social construction of self. Westport, CT: Greenwood Press, Inc. 
Potter, S. (1994). The politics of prejudice: Homosexuals, homophobia, and organizational policy. Association Paper. Author affiliation: James Madison University, Harrisburg, VA, 22807.

Reagan, P. (1981). The interaction of health professionals and their lesbian clients. Patient Counselling and Health Education, 3, 21-25.

Rist, R.C. (1994). Influencing the policy process with qualitative research. In N.K. Denzin \& Y.S. Lincoln (Eds.), Handbook of qualitative research. Thousand Oaks, CA: Sage Publications, Inc.

Rixecher, S. (1994). Expanding the discursive context of policy design: a matter of feminist standpoint epistemology. Policy Sciences, 27 (2-3), 119-142.

Robertson. M. (1992). Lesbians as an invisible minority in the health service arena. Health Care for Women International 13, 155-163.

Sands, R. G. \& Nuccio, K. (1992). Postmodern feminist theory and social work. Social Work, $37(6), 489-494$.

Schwanberg, S. (1990). Attitudes towards homosexuality in American health care literature 1983-1987. Journal of Homosexuality, 19 (3), 117-136.

Simkin, R. (1992). Lesbians face unique health care problems. HealthSharing, Spring/Summer, 40-42.

Smith, D. (1984). Textually mediated social organization. International Social Science Journal, 36 (1), 59-76.

Spaulding, E. (1993). Unconsciousness raising: Hidden dimensions of heterosexism in theory and practice with lesbians. Smith College Studies in Social Work, 63 (3), 247-263.

Stevens, P. (1995). Stuctural and interpersonal impact of heterosexual assumptions on lesbian health care clients. Nursing Research, 44, 25-30.

Stevens, P. (1994). Protective strategies of lesbian clients in health care environments. Research in Nursing and Health, 17, 217-229.

Stevens, P. \& Hall, J. (1988). Stigma, health beliefs, and experiences with health care in lesbian women. Image: Journal of Nursing Scholarship, 20 (2), 69-73.

Stubbs, M. (1983). Discourse analysis: A sociolinguistic analysis of natural language (pp. 1-13). Chicago: The University of Chicago Press.

van Dijk, T. (1990). Discourse \& society: a new journal for a new research. Discourse \& Society, 1 (1), 5-16.

van Dijk, T. (1993). Elite discourse and racism (pp. 1-48). Newbury Park: Sage. 
Wilkerson, A. (1994). Homophobia and the moral authority of medicine. Joumal of Homosexuality, 27, (3/4), 329-347.

Zeidenstein, L. (1990). Gynecological and childbearing needs of lesbians. Journal of Nurse-Midwifery, 35 (1), 10-16. 